\title{
Construcción y comunicación de significados en la música popular ${ }^{1}$ Construction and communication of meanings in popular music
}

\author{
Julián Céspedes Guevara \\ Universidad Icesi, Colombia \\ jcespedes@icesi.edu.co
}

Artículo de investigación científica y tecnológica recibido el 26/04/10 y aprobado el 31/05/10

\begin{abstract}
Resumen
Las tradiciones teóricas de la musicología y de la psicología de la música han estudiado la construcción y comunicación de significados en la música usando un modelo funcionalista de la comunicación. El propósito de esta investigación es estudiar estos fenómenos en el contexto de la música popular usando un método cualitativo y un enfoque constructivista. Para esto, se presentaron dos canciones de una banda de rock y dos de una de Jazz a 20 participantes: 6 músicos de las bandas y 14 oyentes sin formación musical formal. Se les pidió que escucharan cada canción, que indicaran cuándo la música llamaba su atención, y que explicaran cuál era su significado. Los resultados son interpretados como evidencia de que el significado musical no es inherente a música, que la música popular no siempre es percibida como expresiva de emociones; y que la comunicación musical depende de que músicos y oyentes compartan los mismos referentes simbólicos para su significación. Se concluye proponiendo un modelo conceptual constructivista para dar cuenta de la comunicación musical.
\end{abstract}

Palabras clave: Significado musical, Comunicación musical, Expresión de emociones en la música, Percepción de emociones en la música, Música popular

\begin{abstract}
Both musicology and the psychology of music have traditionally approached the construction and communication of musical meanings using a functionalist model of communication. The purpose of this research is to study these phenomena within the context of popular music, using a constructivist theoretical framework. Two songs from a funk-rock band and 2 songs from a jazz band were heard individually by 6 members of the bands and by 14 participants without formal musical training. The participants were asked to indicate the moments in which the music called their attention, and to elaborate on the meaning of each song. The findings were interpreted as evidence that musical meaning is not inherent to music, that popular music is not always perceived an expression of emotions, and that musical communication depends on the existence of shared symbolic referents by musicians and listeners. As a conclusion, a constructivist conceptual model of musical communication is proposed.
\end{abstract}

Key words: Musical meaning, Musical Communication, Emotional expression in music, Perception of emotions in music, Popular music.

1 Este artículo es resultado de la investigación "Meaning and communication in popular music: an exploratory qualitative study" presentada en el año 2005 para obtener el título de Master of Arts in Psychology of Music en la Universidad de Sheffield, Reino Unido. 



\section{Introducción}

¿Qué significa la música? En otras palabras, ¿está “cargada” la música instrumental de significados que son comunicables de músicos a oyentes? Para los musicólogos y compositores llamados “absolutistas” por Meyer (1956: 6), la música no tiene significado, pues para ellos la música carece de la capacidad que tiene el lenguaje para designar objetos extramusicales, y para establecer relaciones del tipo sujeto-predicado que encontramos en las narraciones. Los sonidos musicales, según Stravinsky (Meyer, 1956: 3), sólo designan otros sonidos que ya sonaron o que están por sonar dentro de una misma obra musical. Aquí, el significado de la música queda reducido al "sentido", que implica simplemente relaciones de jerarquía armónica ${ }^{1}$ y direccionalidad (como la dirección de una melodía, por ejemplo).

No obstante, si buscamos la respuesta a las preguntas de arriba examinando las maneras como la gente usa la música en nuestras sociedades contemporáneas, resulta obvio que la música es "significativa" para mucha gente. La música es hoy en día mucho más que un objeto de entretenimiento, se ha convertido en una herramienta importante para la regulación de nuestros estados afectivos (DeNora, 2000; Sloboda y O’Neill, 2001) y en una referencia fundamental para la expresión de subjetividades e identidades colectivas (Reguillo, 2000; McDonald, et al., 2002).

Estos usos sociales de la música como símbolo de estados subjetivos, ideologías e identidades contradicen la postura absolutista, pues parecen indicar una gran idoneidad de la música para "portar” y "comunicar” significados. Aun así, desde el sentido común, generalmente se asume que dichos significados son esencialmente subjetivos, es decir, se piensa que los significados de la música son tan variados como las personas o grupos que la componen, la tocan, la escuchan o la bailan.

Esta posición relativista ha sido desafiada por los musicólogos, quienes por el contrario, se han atribuido la autoridad para buscar y enunciar el significado de las grandes obras musicales del canon occidental. Según esta tradición, el análisis estructural de una obra maestra logra descubrir la habilidad de su compositor para representar bien sea sus estados subjetivos - por ejemplo: "la dicha a través del sufrimiento" de Beethoven-, o el "espíritu de su época” -tal como las relaciones de inequidad de género en las óperas de Bizet- (Cook, 1998; DeNora, 2000). Esta postura es llamada por Meyer (1956: 6) "referencialista” pues plantea que la música tiene una habilidad inherente para referirse a objetos extramusicales, y que una indagación experta es capaz de descubrirlos.

1 En el anexo al final del artículo se encuentra un glosario que explica el significado de los términos musicales técnicos usados en este reporte. 


\section{La música, el "lenguaje de los sentimientos"}

Como se puede observar, la mayoría de las tradiciones doxológicas, sociológicas y musicológicas han asumido la postura "referencialista", pues han aseverado que la música es capaz de cargar significados, tales como: ideas, sentimientos y rasgos de personalidad, valores sociales, creencias religiosas, e incluso mensajes ideológicos (Adorno, 1990/1941). Sin embargo, la mayoría de las veces se ha dado por sentado que el significado fundamental de la música debe buscarse en el dominio de las emociones humanas. Es decir, se considera que la música opera como un "lenguaje de los sentimientos", en el que se pueden comunicar emociones y estados de ánimo del músico a sus oyentes.

A pesar de este consenso, en la filosofía de la música y en la musicología ha persistido la controversia sobre hasta qué punto las emociones son comunicadas de manera específica por la música. Así, Davies y Kivy (Cook, 2001 : 179) argumentan que la música sólo puede expresar emociones básicas tales como la alegría o la tristeza, pero no puede representar emociones más sutiles como la envidia o el orgullo pues este tipo de emociones requieren de la referencia a un objeto externo que la música no puede designar. Por el contrario, Hanslick, asegura que la música solo puede proveer una "vaga agitación", pero no logra representar emociones concretas (en Cook, 2001: 180). La teoría de la potencialidad semántica de Francès afirma de manera similar que la música le presenta al oyente una vaga impresión psicológica, quien a su vez la puede interpretar (y de alguna manera reducir) mediante una etiqueta verbal (Nattiez, 1990 :126).

Ahora bien, en el campo de la investigación científica, los estudios en psicología de la música han sugerido que la posibilidad de transmitir y captar mensajes en la música no deben ser entendidos como el resultado de un proceso puramente racional. Es decir, a pesar de que para "entender" una pieza musical un sujeto debe desplegar una serie de procesos cognitivos (en su mayoría implícitos), esa persona no podrá realmente apropiarse del significado expresado por la música si no entra en contacto con el significado emocional que ésta "porta" (Sloboda, 1998).

Así pues, los fenómenos de la expresión y percepción de emociones en la música han sido objeto de investigaciones desde hace más o menos dos décadas en la psicología de la música. Mientras autores como Eric Clarke se han concentrado en estudiar las estrategias que usan los intérpretes para hacer que la música escrita en una partitura suene "expresiva" y emocional (1995); otros autores como Patrik Juslin han enfocado sus indagaciones en la experiencia del oyente cuando percibe que la música está cargada de emociones. Este autor propone una teoría funcionalista que se resume en su "Modelo de Lentes Expandido" (Juslin, 2005) 
el cual indica cómo ciertas combinaciones de parámetros musicales usados por el compositor y el intérprete (tempo, ritmo, modo, dirección melódica, timbre, volumen, articulación, etc.) son percibidas por el oyente como expresivas de emociones discretas. Por ejemplo,según este modelo, es muy probable que una obra musical que presente una combinación de volumen bajo, timbre opaco, melodía descendente, articulación legato y modo menor sea percibida por un oyente como música que expresa "tristeza". La postura de Juslin, es entonces, equivalente a la que asumen Davis y Kivy desde la filosofía de la música (Cook, 2001 : 179).

Pero la música no sólo es vivida como "cargada" de emociones por los oyentes (i.e. percepción de emociones en la música). También es frecuente que las personas aseguren que la música los conmueve y logra cambiar sus estados afectivos. Este fenómeno, la inducción de emociones por la música, ha sido menos estudiado; el reto que implica ha sido tal vez demasiado grande. Así, Scherer y Zentner (2001) han mostrado cómo a pesar de que en las últimos años han existido varios estudios empíricos que han abordado diferentes aspectos del fenómeno, es muy difícil diseñar experimentos y teorías que estudien sistemáticamente todos los factores que pueden estar involucrados en la experiencia de un oyente que reporta que la música lo conmovió hasta el punto de provocarle una emoción. Para estos autores, un modelo explicativo completo sobre la inducción de emociones debería incluir: la estructura de la música (desde la entonación y el timbre de sonidos individuales hasta la estructura macro como el uso de ritmo y armonía); las variaciones que puede introducir el intérprete (que dependen tanto de su habilidad como de sus intenciones), las cualidades del oyente (disposiciones estables, experticia musical, estado motivacional y anímico actual); y la influencia de la situación en la que está tocando la música en cuestión (características físicas del lugar y connotaciones culturales del evento en que ocurre). Además, para determinar si un oyente tuvo en realidad una emoción, estos autores sugieren que se tomen múltiples medidas, tanto fisiológicas, como autorreportes de los oyentes (Scherer y Zentner, 2001).

En medio de la multiplicidad de estudios que han abordado de manera fragmentada y ateórica el fenómeno de la inducción de emociones por la música, se destacan como excepción la ya clásica propuesta teórica de Meyer (1956), y más recientemente el modelo ITPRA propuesto por Huron (2006), puesto que ambos autores buscan el mecanismo explicativo en la estructura de la música. La idea básica que subyace a ambas teorías (la segunda fuertemente inspirada por la primera), es que al escuchar el flujo de sonidos que llamamos música usamos la misma tendencia a configurar totalidades con sentido como las descritas por la psicología de la Gestalt para la percepción visual. Esto implica que todo el 
tiempo estamos realizando predicciones implícitas o expectativas sobre lo que va a sonar después a partir de lo que hemos escuchado hasta ese momento en la obra musical en cuestión. De acuerdo con estos modelos, cuando los músicos retrasan o incumplen esas expectativas sentimos un cambio en nuestro nivel de activación (arousal), el cual se corresponde a su vez con un cambio en nuestro estado afectivo (la emoción inducida por la música).

Varios estudios exploratorios han encontrado evidencia empírica que indica que ciertas estructuras musicales relacionadas con "la creación, mantenimiento, confirmación, o disrupción de expectativas musicales" (tales como las sincopas, las apoyaturas, la demora en la resolución de una cadencia o cambios súbitos de dinámica o textura) pueden inducir en los oyentes cambios fisiológicos como escalofríos, piloerección o lágrimas (Juslin y Sloboda, 2001: 91; Sloboda, 1991; Goldstein, 1980; Krumhansl, 1997; Konečni, et al., 2007).

Sin embargo, a pesar de lo sugestivas que resultan la teoría de la expectativa de Meyer (1956) y su heredera, la teoría ITPRA de Huron (2006), existen importantes limitaciones en su poder explicativo. Por un lado, hasta el momento no se han desarrollado programas de investigación dedicados a poner a prueba las hipótesis que se derivan estos modelos. Y por otro, al centrarse en la estructura musical, estas teorías no logra explicar por qué un mismo estímulo musical puede producir respuestas tan variadas que van desde la indiferencia hasta escalofríos en diversos oyentes (o en un mismo oyente en distintas ocasiones); y tampoco predicen cuál es la emoción específica que sentirá el oyente, sólo predicen el momento en que se producirá un cambio en su estado afectivo general.

Intentando responder a este último reto, Sloboda y Juslin (2001:93) propusieron la hipótesis de las "protoemociones" - probablemente basados en teorías psicológicas sobre el proceso de elicitación de emociones como la de Schachter y Singer (1962), y la de Rusell y Barrett (1999)-. Según estos autores, la disrupción y confirmación de expectativas motivadas por las estructuras musicales producen en los oyentes cambios súbitos y cortos en su estado afectivo, que son sólo emociones en potencia, o "proto-emociones", las cuales, para constituirse en emociones propiamente dichas deben ser asociadas con una evaluación estética y un contenido semántico proveído por un referente extramusical. Este referente puede ser obtenido por el oyente en datos sobre la situación en la que está escuchando la música, las convenciones culturales asociadas al estilo musical de la obra, las notas del programa de mano del concierto, la letra de la canción (si la tiene), las imágenes y la historia del video musical de la canción, etc. Así, por ejemplo, una obra musical puede producir un sobresalto en el estado afectivo 
general del oyente, y si éste lo asocia a la escena tensionante de una película, entonces el oyente sentirá que la música le indujo un estado emocional de temor.

\section{¿Es posible comunicar significados mediante la música?}

Tanto las teorías musicológicas tradicionales que pretenden descifrar los significados dejados por los grandes músicos en sus obras, como los modelos funcionalistas de la psicología de la música, trabajan bajo el supuesto de que comunicar contenidos (emociones u otros) con medios puramente musicales es en gran medida posible, pues ambas disciplinas usan un modelo de comunicación tradicional. Según este modelo, los mensajes musicales fluyen en un proceso que comienza con las ideas e intenciones del músico, quien las codifica en la partitura, la cual es transformada en sonidos musicales por intérpretes expertos, de tal manera que finalmente estas intenciones e ideas son "leídas" (percibidas) por el oyente. Esta visión lineal de la comunicación musical es ilustrada en el estudio realizado por Juslin y Laukka (2003) en el que se realizó un meta-análisis de 41 investigaciones sobre expresión musical y se encontró que los intérpretes profesionales son capaces de comunicar a sus oyentes cinco emociones básicas (alegría, rabia, tristeza, miedo, ternura) con una exactitud aproximadamente equivalente a la de la expresión facial y vocal de emociones (un nivel de acuerdo de alrededor del 70\%).

Desde un paradigma semiótico diferente, Nattiez (1990:17) propuso un modelo de circulación de símbolos según el cual el mensaje que el emisor pretende presentar al receptor no necesariamente coincide con lo que éste re-construye como interpretación. En el caso de la música, esto implica que no necesariamente el "mensaje" que el compositor o el intérprete colocan en el estímulo sonoro es percibido por el oyente. Aún así, es posible que los frutos del proceso de producción del sonido (llamado proceso poyético por Nattiez) dejen rastros en las características materiales del objeto musical, que puedan ser descifradas de manera selectiva por el oyente (proceso estésico); y, de esta manera, el proceso de comunicación sea al menos parcialmente exitoso.

Esta visión alternativa del proceso comunicativo es coherente con las teorías sociológicas contemporáneas sobre la construcción y circulación de significados en la interacción social. Según estas teorías, el proceso de significación de un objeto no emerge de unas características intrínsecas del objeto que ponen en marcha procesos psicológicos en el individuo, sino que surge en el proceso de interacción entre las personas que debaten (desde diferentes posiciones de poder) cómo debe ser interpretado o significado el objeto en cuestión (Martin, 1995). 


\section{Problemas del paradigma funcionalista de comunicación musical}

Cuando los investigadores en psicología de la música han abordado el problema de la comunicación musical la mayoría de las veces han implementado diseńos experimentales que hacen uso de estímulos musicales elementales tomados de la tradición clásica occidental (frases instrumentales cortas, patrones breves de acordes, etc.), buscando de esta manera controlar y evaluar la influencia relativa de los múltiples factores que pueden influir en la elicitación o en la percepción de emoción-timbre, modo, armonia, dirección melódica, volumen, articulación, ritmo, tempo... etc.- (c.f. Gabrielsson y Lindström, 2001). En este tipo de estudios además es usual que a los músicos se les pida que toquen una pieza expresando una emoción indicada por el investigador, y que a los participantes se les solicite que identifiquen cuál emoción fue interpretada, eligiendo uno de los adjetivos referidos a estados emocionales que se le muestran como opciones (casi siempre cinco). A continuación por supuesto, los investigadores evalúan el grado de coincidencia o acierto entre la emoción "expresada" por el músico y la emoción percibida por los oyentes (Juslin, 2000).

Es evidente que ante un fenómeno inherentemente multivariado y complejo como el de la comunicación de emociones mediante la música, este paradigma experimental ha avanzado bastante en términos de validez interna. Sin embargo, al mismo tiempo las estrategias que estos estudios han empleado para controlar variables han representado su principal falencia. Así, la pobreza musical de los estímulos usados, la probabilidad de que las respuestas de los sujetos sean un artificio producido por los formatos cerrados de respuesta, y las instrucciones igualmente restrictivas dadas a los músicos que tocan los estímulos musicales, le restan valor a las explicaciones que estas investigaciones hacen de los fenómenos estudiados.

Pero más allá de las restricciones que impone el método experimental, es el modelo teórico funcionalista en el cual basan este tipo de investigaciones su principal limitación epistemológica. Los autores que trabajan con este modelo asumen sin cuestionar las premisas de las teorías musicológicas según las cuales el significado musical "está ahî" en la obra, trascendiendo los condicionamientos históricos o culturales de su producción o interpretación, y esperando a ser percibido por un oyente experto (Cook, 2001).

Esta ideología individualista se observa claramente en los argumentos que estos autores funcionalistas esgrimen para afirmar que la comunicación musical está basada en mecanismos perceptivos de origen filogenético. Basados en teorías psicológicas de corte evolucionista como la de Ekman (1975), estos investigadores plantean la existencia de patrones universales de expresión de emociones en la 
voz humana (Scherer, et al., 2001); y que los compositores e intérpretes usan dichas convenciones acústicas de tal manera que los oyentes perciben emociones discretas en la música, pues están "biológicamente preparados" para hacerlo (Juslin y Laukka: 2003; Juslin, 2005 : 95).

A pesar de lo atractivas que resultan este tipo de teorías, (pues nos hacen pensar en la supuesta funcionalidad adaptativa de la música para nuestra especie), este tipo de explicaciones son problemáticas, ya que tanto los musicólogos como los psicólogos funcionalistas olvidan que la música clásica occidental es tan sólo un tipo de música entre la enorme diversidad de músicas que existen y han existido en la historia de la humanidad. Y sobre todo, olvidan que tal como sucede con cualquier otra forma de arte, nunca experimentamos la música como un "estímulo neutro" o como un estímulo cuyo significado está dado de antemano por las características físicas del sonido. Por el contrario, inevitablemente abordamos la música en el contexto de marcos de referencia de origen sociocultural que sesgan nuestra interpretación de los sonidos dentro de las fronteras impuestas por nuestro sistema perceptual (Dibben y Windsor, 2001). Así, autores como Cook (1998) y Small (1999), han demostrado que es posible que una misma obra musical cambie de significado con el paso del tiempo a pesar de que los sonidos que la conforman no cambien -por ejemplo, las sinfonías de Beethoven que en la época de su estreno eran acontecimientos artísticos revolucionarios, hoy representan para sus audiencias los valores del status quo (Small, 1999).

Desde esta perspectiva, resulta por lo menos ingenuo asumir que los estímulos musicales elementales y los controles implementados en los diseńos experimentales logran limpiar a la música de su significado cultural y convertirla en un estímulo que es percibido como "sonido puro". Por el contrario, es probable que precisamente un sujeto que participe en estos experimentos de percepción de emociones seleccione alguno de los adjetivos emocionales que se le presentan como lista de opciones porque, por un lado, asume que el investigador espera que lo haga y, por otro, porque le asigna un significado a la música haciendo uso de las convenciones culturales que le dicen que, por ejemplo, la música de piano, suave y lenta, ha sido frecuentemente usada en las películas para acompañar escenas románticas y, por lo tanto, es expresiva de "amor" o "ternura".

Por otro lado, la decisión de los investigadores de psicología de la música desde sus inicios de estudiar la experiencia de músicos y oyentes con la música clásica occidental ha legitimado implícitamente los valores estéticos de esta tradición, pues se parte del supuesto de que el mayor grado de complejidad estructural de esta música la haría al mismo tiempo más digna de ser estudiada científicamente. Esta elección empírica deja, por supuesto, por fuera de su indagación la 
experiencia de la mayoría de sujetos que en nuestras sociedades contemporáneas componen, aprenden, practican, escuchan y aprecian la música popular ${ }^{2}$ en sus vidas cotidianas.

Pero no sólo se trata de que en la vida cotidiana la música popular sea más difundida, el punto es también que las prácticas de su producción, distribución y escucha no coinciden con las tradiciones, valores y actitudes que se esperan del músico y del oyente de la música clásica. En la música popular parámetros musicales como el timbre y el uso de efectos de sonido producidos en el estudio de grabación son más valorados que el uso de armonías complejas; es bastante común que los artistas que no tengan formación profesional sean los más escuchados; la escucha de música sin letra es más bien rara, y es típico que las personas escuchen piezas musicales completas (en vez de fragmentos). Por otra parte, en algunos géneros populares como el rock, sus seguidores valoran tanto los sonidos de la "obra musical", como las letras de las canciones, la puesta en escena, el carisma, el atractivo físico del artista, y su capacidad para convocar una comunidad de seguidores que lo consideran como "auténtico". En el caso de la música popular, entonces, los parámetros para su valoración estética o para una discusión sobre su significado pasan necesariamente por los usos sociales que tiene esta música (Frith, 1987; Frith et al., 2006).

\section{Objetivos y estrategia metodológica}

El objetivo general de esta investigación es explorar la validez de la implementación de un modelo constructivista para dar cuenta de los fenómenos de la construcción y comunicación de significados en la música. Este modelo representa una postura crítica ante el paradigma dominante en psicología de la música, el cual trabaja con tres supuestos básicos: a) la idea de que la música tiene un significado "inherente"; b) la idea de que este significado es comunicado de manera diáfana de compositor a intérprete y de éste al oyente, y c) el supuesto de que los diseños experimentales son los más adecuados para dar cuenta de estos fenómenos.

En este mismo orden de ideas, otro objetivo de este trabajo es examinar el alcance que tiene el uso de una estrategia metodológica cualitativa para acercarse a la comprensión de este objeto de estudio. Más que poner a prueba hipótesis previas, lo que busca es aproximarse a la experiencia de los músicos y los oyentes en condiciones más cercanas a las que ocurren en la vida cotidiana, buscando

2 En este estudio se usará el término "música popular" para designar aquella música que no hace parte de la tradición clásica, canónica o de "conservatorio”. Es decir, aquella música de orientación comercial, con difusión masiva y ligada a la práctica amateur, tal como el pop, el rock y el jazz "easy-listening”, entre otras. Para una discusión sobre las connotaciones del término, véase Shuker, 2005. 
así que los hallazgos tengan mayor validez ecológica que los de la tradición funcionalista en psicología de la música.

Estos dos grandes objetivos dan lugar a cuatro objetivos específicos, que se presentan a continuación en forma de interrogantes:

1. ¿Tienen los músicos populares la intención consciente de comunicar un mensaje a su audiencia? ¿Es ese mensaje de tipo "emocional"?

2. Si es así, ¿¿cuáles son las "señales" musicales que usan para comunicar dicho mensaje o emoción? ¿Cómo las usan?

3. ¿A partir de qué "señales" construyen los oyentes su interpretación de las piezas musicales? ¿Coinciden con las usadas por los músicos? ¿Cómo las usan para construir a partir de ellas un mensaje?

4. ¿Hasta qué punto la interpretación que hacen los oyentes acerca del "mensaje" o emoción de la canción coincide con los que intentaron comunicar los músicos?

Para responder a estas preguntas-objetivo se adoptó un procedimiento similar al tipo cuasi-experimental, en el cual a los participantes se les pidió escuchar y narrar su experiencia con respecto a las canciones propuestas por el investigador, en entrevistas semiestructuradas. La información proveída por los participantes fue codificada usando una técnica de análisis fenomenológico interpretativo, para acercarse así a la perspectiva de los participantes, en vez de trabajar con categorías preestablecidas por la teoría (Smith, et al., 1999).

\section{Participantes}

Un total de veinte sujetos (12 hombres, 8 mujeres) participaron en esta investigación, todos de edades entre 20 y 33 años de edad. En el momento de la investigación todos vivían en Inglaterra, en calidad de egresados o estudiantes de pregrado y postgrado de la Universidad de Sheffield. Estos participantes fueron escogidos en forma intencional, no a partir de un método de muestreo estadístico sino a través de la red de contactos con que contaba el investigador entre sus conocidos en la ciudad.

Los participantes en el estudio se dividen en dos grandes categorías:

Músicos. Luego de indagar en varias agrupaciones musicales, se decidó trabajar con dos bandas activas en el circuito musical de la ciudad de Sheffield (Inglaterra) que trabajaban en géneros de música popular y que manifestaron su disposición para colaborar con la investigación. La primera era una banda de funk-rock, constituida por cuatro integrantes (vocalista, guitarrista, bajista 
y baterista), ninguno de los cuales tenía formación musical profesional. Fue posible entrevistarlos a todos. La segunda banda (de la cual sólo se pudieron contactar a la cantante y el pianista), es una banda de jazz estilo easy-listening, cuyos miembros tenían estudios de pregrado en música.

Oyentes. Este grupo está constituido por catorce participantes entre 20 y 33 años de edad ( 7 hombres, 7 mujeres) que no habían recibido educación musical y que sólo en dos casos estaban involucrados en tocar instrumentos de manera esporádica y aficionada. Ninguno de estos participantes conocía con anticipación las canciones que se les presentaron para que escucharan durante la entrevista.

Debido a que la comprensión de la letra de las canciones puede facilitar la comunicación de los mensajes de los músicos a los oyentes, se decidió seleccionar como oyentes a dos subgrupos de participantes según su origen cultural y habilidad para hablar inglés.

Así, la primera mitad de los oyentes eran de origen británico y por tanto, perfectamente capaces de hablar y entender inglés. Además, en la entrevista se evidenció que estaban familiarizados con los géneros de las bandas entrevistadas, aunque no siempre fuera su tipo de música favorita (a este grupo se le denominará de ahora en adelante "británicos").

Los siete sujetos restantes eran de origen extranjero y el inglés no era su idioma nativo (tenían orígenes culturales diversos: China, Taiwán, Bolivia, España e Italia). A pesar de que lo ideal hubiera sido que además no estuvieran familiarizados con los géneros musicales de las bandas entrevistadas, esto solo fue parcialmente posible, pues en un extremo estaban los participantes de origen cultural chino, quienes estaban menos habituados a estos tipos de música, y en el otro, algunos participantes que a pesar de no entender completamente la letra de las canciones, conocían el estilo al que pertenecían (a partir de este momento a este grupo de oyentes se le denominará "extranjeros").

\section{Procedimiento}

Con el fin de acercarse de manera más detallada a conocer el proceso de construcción de significados musicales en el momento mismo en el que ocurre, se implementó un procedimiento basado en el usado por Waterman (1996). En este caso, consistió en pedirles a los participantes de manera individual que escucharan las canciones de principio a fin usando audífonos y que levantaran su mano cada vez que la música o la letra "les llamaran la atención" o simplemente "provocaran que algo les sucediera". Una vez que cada participante terminaba de 
oír cada canción, el investigador le pedía que la escucharan de nuevo, pero esta vez con parlantes. El investigador entonces pausaba la canción en cada momento en el que el oyente había levantado la mano durante la escucha con audífonos, y le preguntaba por qué razón levantó la mano en cada ocasión.

Una vez finalizado esta fase, el investigador le proponía al oyente una serie adicional de preguntas sobre el significado o mensaje de la canción y la emoción que expresaba de forma predominante. También en este momento la entrevista se complementaba con preguntas sobre su familiaridad con los géneros musicales de las canciones, su nivel de educación musical, y su música favorita.

Los participantes en la categoría de oyentes escucharon las cuatro canciones (dos de cada banda). Los músicos en cambio escucharon sólo sus propias canciones. Además, a este grupo de participantes se les pidió que levantaran la mano no sólo cada vez que la música o la letra causaran que "algo les sucediera", sino que además la levantaran cada vez que percibieran que ellos mismos u otro miembro de su banda estaban siendo "expresivos musicalmente". También en el caso de los músicos, este procedimiento fue complementado con preguntas adicionales sobre su formación e influencias musicales.

\section{Descripción de las canciones presentadas a los participantes ${ }^{3}$ \\ Canciones de la banda de Funk-Rock}

Ambas canciones de la banda de Funk-Rock (Cellarhigh: http://www.myspace.com/cellarhigh) son interpretadas con la instrumentación tradicional de un conjunto tradicional de rock: vocalista masculino, guitarra eléctrica, bajo eléctrico y batería. En algunas puntas en las canciones la guitarra y el bajo introducen efectos digitales.

\section{Canción 1: Sirens Call}

Eta es una canción de rock con un coro melódico que la hace sonar cercana al estilo "Indie". A pesar de que no es muy rápida $(\mathrm{bpm}=120)$, sus arreglos y estilo de canto cercano al rap dan la sensación de ser muy "movida".

La letra habla de una persona que sale una noche y va a una discoteca, donde siente la atracción de la pista de baile, como el llamado de sirenas. El coro repite la frase "I’m feeling beautiful", describiendo la sensación de éxtasis y felicidad mientras se baila.

La introducción de la canción consiste solamente de una guitarra acústica tocando acordes en Mi mayor y Si bemol mayor, con un silencio cada 6 tiempos, 
lo cual produce un efecto de tensión armónica que no se resuelve. Las estrofas son cantadas por en un estilo de "rap" rápido por el cantante, y son acompañadas por la misma armonía, esta vez interpretada por el bajo que tiene un efecto fuzz y la misma guitarra acústica del comienzo.

En el puente, el cantante usa un estilo melódico, acompañado por un arpegio en la guitarra eléctrica. Este puente es dividido en dos partes por una sección "pesada" de dos compases en las cuales el cantante grita y los otros instrumentos tocan en un estilo "caótico" y distorsionado en cada tiempo.

El coro de la canción se basa en una armonía ascendente (Sol, La, Si bemol, Do) y la melodía vocal es muy rítmica. Después del primer coro la canción repite básicamente la misma forma con pequeñas variaciones como la introducción de voces de acompañamiento. Luego del segundo coro hay un solo de guitarra muy rápido, una repetición del puente, cantado en falsete y un coro final cantando de manera menos acentuada.

\section{Canción 2: Give some loving}

En términos generales esta es una canción estilo funk-rock, pero al tiempo posee otros elementos que la hacen interesante para los objetivos de este estudio: combina una letra romántica con otras secciones más "bromistas", algunas secciones musicalmente movidas con un interludio melódico y un coro con elementos de jazz.

La letra de la canción empieza pintando la escena de un hombre que le habla a una mujer junto a la cual despierta en la cama. Luego, en el coro, él hace una ambigua y bromista declaración de amor: le dice que no puede vivir sin ella, pero al mismo tiempo le dice que debe tener cuidado con lo que desea, porque es posible que su pretensión de que él sea su novio se haga realidad. El coro termina con una repetición del título de la canción: "dame un poco de amor". La segunda estrofa empieza con una descripción de la belleza de esta chica, pero termina con una broma: él empieza diciendo que ella es tan hermosa que puede perder el control de su propia mente... y de su ropa, de hecho, se la va a quitar toda. La letra del interludio melódico es la más seria de la canción: habla de cómo esta chica puede traerle felicidad cuando el mundo lo deprime.

Musicalmente la canción comienza con un ritmo suave y andante en la batería con un acompañamiento funky en la guitarra acústica. La línea vocal empieza casi suspirada, pero se hace más intensa conforme avanza la canción. Luego de una pausa repentina, el coro empieza con un estilo "juguetón”, acompañado por un estilo walking bass en el bajo y la guitarra con acordes agudos estilo ska. El 
coro termina con los vocales repitiendo "dame un poco de amor" con el acompańamiento de un motivo funky en el bajo.

La segunda estrofa es acompañada por los instrumentos tocando alrededor de un motivo funky en la guitarra y el bajo. Mientras la letra introduce la parte graciosa ('I might lose control of my mind... my trousers...'), el acompañamiento evoluciona hacia el coro jazzy, excepto que esta vez la frase final "give me some loving" es cantada con una nota larga que introduce el interludio.

Este interludio es caracterizado por frases melódicas en la voz, acompañadas por la guitarra repitiendo un acorde a través de un efecto delay ping-pong que produce un sonido de ecos y mucha reverberación, lo cual da la impresión de que la música se está interpretando en un espacio grande y vacío. La canción entonces progresa hacia la sección "pesada" en la que el cantante vocaliza en un estilo casi gritado, mientras la guitarra hace uso de la distorsión y la batería usa más los platillos. Justo cuando termina esta sección, hay una línea funky en la guitarra, la canción regresa al coro y termina con un final bastante convencional.

\section{Canciones de la banda de Jazz}

Ambas canciones de la banda de Jazz ("Black Coffee": http://co-lo.night-shade. org.uk/ nick/new bc site/) son interpretadas con una vocalista femenina, un piano, un saxofón tenor, un bajo eléctrico y una batería.

\section{Canción 3: Black Coffee}

La versión que la banda hace de esta canción es más cercana a la versión original de Peggy Lee (1948) que a la más conocida de Ella Fitzgerald (1960). La letra describe a una mujer que habla en primera persona sobre su estado de aburrimiento y soledad que le provoca esperar a que su hombre regrese a casa. Todo lo que hace es tomar café negro y fumar cigarrillos. En el coro, reflexiona sobre el rol resignado de las mujeres en la sociedad: "a man's born to go and loving, a woman's born to weep and fret".

Musicalmente hablando, la canción empieza con un estilo blues-jazz interpretado en el piano, el bajo y la batería presentando la progresión armónica que subyace a la mayoría de la canción (Mi bemol - Mi). Cuando la voz llega a la segunda parte de la estrofa, el saxofón toca un adorno y el acompańamiento cambia. Cuando la armonía llega a la séptima de dominante (V7) y la letra dice "never known a Sunday", la música hace una pequeña pausa antes de resolver la cadencia y la cantante hace un portamento en la última sílaba ("in this weekday room”). La segunda estrofa sigue básicamente el mismo esquema. 
Cuando la canción llega al coro el bajo comienza a tocar un estilo walking bass, el acompańamiento es un poco más activo y la melodía sube a un registro más alto. Luego de la tercera estrofa (que es muy similar a las anteriores) el saxofón empieza un solo, acompañado discretamente por el resto de los instrumentos. Durante la primera mitad del solo las frases son cortas y en el registro medio del instrumento, pero súbitamente el saxofón hace una nota larga (en el séptimo grado mayor de la escala: Re bemol) y a partir de ese punto el solo consiste en frases legato más rápidas tocadas en un estilo blues. Una vez que el solo de saxofón termina, empieza un breve solo de bajo, acompañado por la batería.

Finalmente la canción presenta el coro y la tercera estrofa de nuevo que esta vez tiene una presencia más notoria del piano y de frases del saxofón. Termina con la misma pausa antes de resolver la cadencia al final de la estrofa y tocando de nuevo el motivo armónico por cuatro compases (Mi bemol- Mi).

\section{Canción 4: You took advantage of me}

La versión de la banda de esta canción es más rápida que la original y no incluye la tradicional introducción que contextualiza el tema que se cuenta en la letra ("A girl's heart must go to someone... so I loved my horse... but horses are frequently silly... So I picked you").

La letra de la canción usa un lenguaje gracioso para describir a una persona que acepta que ha caído en los encantos de su amante y no tiene sentido resistirse. Sin embargo, cuando el coro repite "so lock the door and call me tours, you took advantage of me", no es claro si esto debe tomarse como una señal de enojo o de ironía.

La música empieza con una introducción en el piano lenta y corta que termina con un acorde en el punto de séptima de dominante de la cadencia (V7). De repente la voz y el resto de los instrumentos entran con un tempo mucho más rápido. De ahí en adelante, la canción tiene un ritmo ágil y adornos rápidos en el saxofón.

Luego de cuatro estrofas muy similares entre sí, comienza un solo de piano con frases cortas y luego evoluciona al uso de acordes y frases rápidas en el registro agudo del instrumento. Este solo es seguido por una sección de canto en estilo scat en el que la vocalista alterna las sílabas con la repetición de la frase "you took advantage of me". Cuando finaliza el solo vocal, el piano toca de nuevo el acorde grave con el que terminó la introducción de la canción. La canción recomienza con tempo lento, y poco a poco entran el resto de los instrumentos, mientras la canción se acelera de nuevo hasta el tempo original. El saxofón toca líneas muy rápidas en respuesta a las del cantante en esta sección. Finalmente la canción 
llega al punto del coro donde de nuevo hace una pausa, la cantante repite los versos del coro y finalmente los instrumentos resuelven suavemente la cadencia al regresar al acorde de tónica.

\section{Resultados}

En primer lugar se presenta una descripción de aquellos momentos que los participantes (tanto músicos como oyentes) destacaron levantando la mano porque algo en la canción "les llamaba la atención". En la siguiente sección se organiza la información proveída por los sujetos alrededor de las preguntas que se plantearon como objetivos de la investigación.

\section{Eventos destacados por los participantes}

Hubo un gran número de momentos destacados por los participantes mientras escuchaban las canciones. En promedio levantaron la mano 2,94 veces cada 10 segundos. Algunos eventos en las canciones motivaron que hasta el $75 \%$ de los participantes levantaran la mano para señalar que les había llamado la atención por alguna razón.

El criterio para estimar cuáles eventos eran más comunes se basó en el método de Waterman (1996). Así, un evento fue considerado significativamente común si era destacado por un número de participantes igual o mayor a 2 desviaciones estándar sobre el número promedio de respuestas en alguno de los grupos (músicos u oyentes) para esa canción.

A continuación se presenta la lista de los momentos destacados por los participantes en cada canción, junto a una descripción de las propiedades musicales del fragmento que estaba sonando en ese momento. Estas propiedades son tomadas de la lista que presenta Sloboda en su estudio sobre reacciones emocionales a factores estructurales de la música (1991).

\section{Canción 1 Banda de Funk-Rock: "Sirens Call"}

\begin{tabular}{|l|l|}
\hline $0: 16$ [Entrada de la voz] & Cambio de textura y dinámica \\
\hline $0: 38$ [Sección "pesada"] & $\begin{array}{l}\text { Cambio repentino de textura y dinámica con } \\
\text { más volumen }\end{array}$ \\
\hline 0:49 hasta 1:04 [Coro] & $\begin{array}{l}\text { Progresión armónica ascendente, Melodía con } \\
\text { intervalos más amplios, cambios en la textura, } \\
\text { ritmo más marcado. }\end{array}$ \\
\hline $1: 07$ [Segunda presentación de la introducción] & Cambio súbito de armonía, textura y dinámica. \\
\hline $1: 34[$ Sección pesada] & $\begin{array}{l}\text { Cambio repentino de textura y dinámica con } \\
\text { más volumen. (Igual que la primera vez). }\end{array}$ \\
\hline
\end{tabular}




\begin{tabular}{|l|l|}
\hline 1:45 hasta 2:00 [Coro con "yeahs"] & $\begin{array}{l}\text { Armonía ascendente en la guitarra y el bajo, } \\
\text { melodía descendiente en las segundas voces. }\end{array}$ \\
\hline 2:01 hasta 2:16 [Solo de guitarra] & $\begin{array}{l}\text { Cambio en dinámica, timbre, y textura. Notas } \\
\text { rápidas, y muy agudas. }\end{array}$ \\
\hline 2:13 hasta 2:17 [Solo de guitarra: Octavas] & $\begin{array}{l}\text { Evento prominente no esperado. Cambio de } \\
\text { rango melódico súbito, notas muy agudas con } \\
\text { respecto al resto del solo. }\end{array}$ \\
\hline $\begin{array}{l}\text { 2:20 [Repetición del Puente con falsetto melódico } \\
\text { yuitarra acústica] }\end{array}$ & $\begin{array}{l}\text { Cambio súbito de timbre en la voz, en la textura } \\
\text { y dinámica del resto de la banda. }\end{array}$ \\
\hline
\end{tabular}

\section{Canción 2 Banda de Funk Rock: "Give me some loving"}

\begin{tabular}{|l|l|}
\hline 0:00 to 0:15 [Introducción] & $\begin{array}{l}\text { Apoyaturas melódicas en la segunda guitarra, } \\
\text { síncopa repetida en el bajo. }\end{array}$ \\
\hline $0: 33$ [Pausa] & $\begin{array}{l}\text { Evento prominente no preparado. (Silencio } \\
\text { súbito). }\end{array}$ \\
\hline 0:56 [Motivo Funky en el bajo] & Secuencia melódica, cambio en textura. \\
\hline 1:07 [Segunda presentación de la introducción] & Cambio súbito de armonía, textura y dinámica. \\
\hline $\begin{array}{l}\text { 1:42 [Interludio melódico, introducido por notas } \\
\text { largas en la voz] }\end{array}$ & $\begin{array}{l}\text { Cambio en timbre y textura, entonación más } \\
\text { alta en las voces. }\end{array}$ \\
\hline 1:52 [Interludio melódico] & $\begin{array}{l}\text { Nueva armonía, secuencia melódica, cambio } \\
\text { de textura. }\end{array}$ \\
\hline 2:10 [Sección "pesada", voz casi gritada] & $\begin{array}{l}\text { Cambios en timbre, textura, dinámica y ar- } \\
\text { monía. }\end{array}$ \\
\hline 2:29 [Motivo Funky en la guitarra] & $\begin{array}{l}\text { Secuencia melódica, articulación staccato, ritmo } \\
\text { marcado. }\end{array}$ \\
\hline 3:06 ['Final convencional'] & $\begin{array}{l}\text { Resolución de la cadencia luego de una pequeña } \\
\text { pausa. Cambio de textura. }\end{array}$ \\
\hline
\end{tabular}

\section{Canción 3 Banda de Jazz: "Black Coffee"}

\begin{tabular}{|l|l|}
\hline $1: 11$ [Portamento en la voz en "dreams"] & $\begin{array}{l}\text { Secuencia melódica, demora en la resolución } \\
\text { de la cadencia. }\end{array}$ \\
\hline 1:29 [Portamento en la voz en "weep and fret"] & $\begin{array}{l}\text { Cambio en la dirección melódica, cambio ar- } \\
\text { mónico y en la dinámica. }\end{array}$ \\
\hline 2:13 hasta 3:19 [Solo de saxofón] & Cambio en textura, secuencia melódica. \\
\hline 2:44 [Solo de saxofón: Nota larga] & Evento prominente no preparado. \\
\hline 2:53 [Solo de saxofón: frases rápidas] & Cambios en dinámica y en dirección melódica. \\
\hline 3:03 [Solo de saxofón: escala ascendente] & Secuencia melódica. \\
\hline 3:20 hasta 3:46 [Solo de bajo] & Cambios en dinámica y textura. \\
\hline
\end{tabular}


Canción 4 Banda de Jazz: "You took advantage of me"

\begin{tabular}{|l|l|}
\hline 0:00 hasta 0:12 [Introducción] & $\begin{array}{l}\text { Apoyaturas melódicas, secuencia armónica } \\
\text { descendiente }\end{array}$ \\
\hline 0:14 [Entrada de la voz] & Cambios súbitos en textura, dinámica y ritmo. \\
\hline 0:52 [El solo del piano empieza con frases cortas] & Apoyaturas melódicas, secuencia armónica. \\
\hline $1: 13$ [El piano de solo se complejiza] & $\begin{array}{l}\text { Cambio en armonía y dinámica, secuencia } \\
\text { melódica }\end{array}$ \\
\hline 1:25-2:00 [Sección "scat" en el canto] & Cambio de textura, síncopa repetida en piano. \\
\hline $2: 38[$ Accelerando] & $\begin{array}{l}\text { Secuencia armónica y melódica, cambio en } \\
\text { dinámica y en tempo. }\end{array}$ \\
\hline
\end{tabular}

Evidentemente, la elaboración de esta lista de eventos destacados en las canciones, a partir de criterios meramente estadísticos, deja por fuera varios fragmentos sobre los cuales algunos participantes fueron particularmente elocuentes. Sin embargo, la existencia de estos eventos musicales "objetivos" -en cuanto son resaltados tanto por la mayoría de los músicos como por la mayoría de los oyentes-, abre la posibilidad de que se establezca la comunicación entre los músicos y su audiencia. En otras palabras, si al escuchar las canciones ambos grupos enfocan su atención a los mismos momentos estructurales, es más probable que construyan significados similares, a que lo hagan si cada grupo pone su atención en momentos muy diferentes.

\section{¿Tienen los músicos la intención consciente de comunicar un mensaje a su audiencia? ¿Es ese mensaje de tipo "emocional"?}

Según la tradición musicológica (y el sentido común también), se espera que cuando un músico compone e interpreta sus obras, lo haga teniendo muy claro cuál es el mensaje general que intenta transmitir a su audiencia, y que por tanto las decisiones sobre los arreglos o sobre su interpretación sean coherentes con este mensaje. El caso de los seis músicos entrevistados en esta investigación no apoya claramente este supuesto.

Así pues, en ambas bandas fueron solamente los cantantes quienes reportaron conocer a cabalidad el "mensaje" de la canción; en todas las ocasiones articularon una narrativa que giraba alrededor de la letra de las canciones. Los demás músicos en cambio, afirmaban tener solo una idea general del feeling o vibe $e^{4}$ general de la canción, y muchas veces declararon no conocer con exactitud qué dice la letra.

4 Este feeling ("sentimiento") o vibe ("vibra”) es un término ambiguo que usan los músicos para referirse a la impresión general, el nivel de energía (activación) o el "aura emocional” que se percibe de manera muy intuitiva al tocar o escuchar una pieza musical. 
Yo creo que [la canción] tiene una idea común que la atraviesa, en la letra, es este tipo queriendo está con la chica, levantándose juntos a la mañana siguiente, y él disfruta el hecho de que estén juntos, ya sabes, el rayo de sol, etc., [...] Él está tratando de decirle cómo se siente con ella, pero no es muy bueno expresándolo, así que en vez de ser serio, bromea y es gracioso, y luego progresa a ser serio por un segundo, y entonces es como si dijera: 'ya es suficiente de tanta seriedad' y vuelve a ser gracioso de nuevo.

[Cantante de la banda de Funk-Rock, sobre "Give me some living"]

Investigador: ¿De qué se trata esta canción?

Respuesta: Se siente como una canción de jazz para la noche... Es un poco monótona, deprimente, tiene un ritmo repetitivo, [lo canta].

[Pianista de la banda de Jazz, sobre "Black Coffe"]

\section{¿Cuáles son las señales musicales que usan los músicos para comunicar su mensaje? ¿Cómo las usan?}

Los cantantes ven su rol similar al de un actor o actriz que debe darle vida a la narrativa contenida en la letra ante el público. Esta atención a la letra de la canción hizo que cuando levantaran la mano para resaltar un evento de una canción, la justificación que dieran fuera muy coherente con la "historia" que narra la canción. Así por ejemplo, la cantante de la banda de jazz destacó un momento en que realiza un portamento y explicó esa decisión en términos de la letra: "allí uso una voz más aguda, para sonar sumisa, un poco patética, cuando canto que no hay objeto en resistirse" ["so what's the use, you cooked my goose, you took advantage of me"].

Los músicos instrumentistas en cambio, no solieron destacar eventos unidos por una narrativa coherente y unificada. La mayoría de las veces que levantaron la mano para resaltar un momento de la canción fue para destacar aspectos musicales de la misma, no relacionados directamente con el mensaje que denota la letra:

Ese es un buen cambio en la canción, te toma por sorpresa... también el estilo de canto cambia, aunque en realidad no sé qué dice la letra allí... Creo que sirve para llevar a la canción a otro nivel"

[Bajista de la banda Funk-Rock sobre "Give me some living"].

Allí intento que la canción suba un poco de energía... siempre he pensado que deberíamos subir un poco la canción en la última estrofa y relajarla antes que vaya al coro

[Pianista de la banda de Jazz, sobre "Black Coffee"].

Cuando se les preguntó a estos músicos instrumentistas si estos eventos de las canciones que destacaron como "particularmente expresivos" tenía un mensaje 
emocional, la mayoría respondió afirmativamente, pero no supieron explicar de qué emoción se trataba. Usaban en cambio palabras como "comunicativo", "expresivo", "energético", "poderoso", o se referían a subir de nivel la música, a llevarla al "clímax", o a presentar un contraste con respecto a lo que sonaba antes, etc.

I: ¿Consideras que hay una emoción particular que intentabas expresar con tu solo [de guitarra]?

R: Lo que hago es llevar la canción al clímax, por eso uso el pedal whammy para introducir las octavas... Se pone más rápido y como más alto, con las notas del solo, así que es como que lo estoy llevando a un clímax [...] Trato de que la guitarra chille, como si estuviera maltratándola, lo cual hace un contraste total con la parte que sigue.

[Guitarrista de la banda Funk-Rock sobre "Siren's call”].

[Hablando sobre el momento del solo de saxofón en el que éste hace frases ascendentes]: Yo traté de hacer énfasis [en el piano] en el punto emocional más alto, en el décimo compás del blues de 12 compases, el momento donde entra la dominante. Allí como que cae y se detiene y vuelve a la tónica. Siempre me ha parecido que ese es el momento de mayor emoción en un solo, y de la pieza como totalidad, crece hasta ese punto.

[Pianista de la banda Jazz sobre "Black coffee"].

Como puede observarse, a pesar de que estos músicos consideraron que por momentos tocaban de manera "expresiva", no tenían claro exactamente qué era lo que "expresaban", incluso cuando mencionaron que estaban expresando emociones. Sabían que sus decisiones interpretativas podían tener un efecto en los oyentes, pero no necesariamente lo hacían con una intención consciente de transmitir "un mensaje" o "emoción".

\section{¿A partir de qué "señales" construyen los oyentes su interpretación de las piezas musicales? ¿Coinciden con las usadas por los músicos?}

Ya se mencionó anteriormente que tanto oyentes como músicos tendieron a destacar los mismos momentos de las canciones, probablemente debido a su importancia estructural (la repetición de un coro), o a que corresponden a momentos en que se retrasan o se incumplen las expectativas que el fluir de la música ha generado en el proceso perceptual de quien la escucha (Meyer, 1956).

De hecho, es muy probable que las razones que los oyentes reportaron para levantar la mano no sean las únicas que hicieron que un evento de la canción se les presentara como atractivo. Esto se puede inferir a partir de aquellos momentos en que por ejemplo, los oyentes afirmaron haber levantado la mano porque la voz 
del cantante les llamó la atención, pero si observamos la estructura de la canción, notamos que ese momento coincide además con el retraso en la resolución de una cadencia. Esto indica que hay un nivel de procesamiento cognitivo de la música de carácter implícito por parte de los oyentes, que hace que enfoquen su atención hacia momentos determinados de las canciones, pero que no necesariamente puedan dar cuenta completamente de las razones por las cuales les "atrajo".

I: ¿Por qué levantaste la mano en este momento? [Final de la segunda estrofa, cuando la banda retrasa la resolución de la cadencia].

$\mathrm{R}$ : Por la letra, me gustó. Me puse a escuchar la letra en ese momento, con lo de "I'm hanging out on Mondays, my Sunday dreams... to dry"

[Mujer extranjera, sobre "Black Coffee"]

$\mathrm{Al}$ igual que sucedió con los músicos instrumentistas, en muchas ocasiones los oyentes destacaron eventos que les sonaron muy intensos o expresivos, pero no siempre pudieron aclarar en sus respuestas si lo que estaba siendo expresado era una emoción concreta. Más bien recurrieron de nuevo a términos que se refieren al nivel de activación o energía de la música.

I: ¿Por qué levantaste la mano en este momento? [Sección "pesada”]. R: Suena como que se ha puesto muy pesado, ya sabes, tiene ese ritmo de guitarra machacante atrás (...) Y él está cantando muy poderosamente en ese momento también.

I: ¿Crees que ellos están expresando alguna emoción en ese punto? R: Se siente como mucha energía... [Piensa un rato]... No podría decir una sola emoción, no.

[Hombre británico, sobre "Give me some loving"]

Por otra parte, no todos los eventos que los oyentes destacaron fueron usados por éstos para inferir cuál era el mensaje de la canción. Por ejemplo, la mayoría de los oyentes levantaron la mano al escuchar una nota particularmente larga en el solo de saxofón que aparece súbitamente luego de una serie de frases cortas en la canción Black Coffee, pero cuando se les preguntó sobre el mensaje de la canción, no mencionaron este evento musical como una "pista" o "clave" para inferir dicho mensaje. En esto también coinciden con la actitud de los músicos instrumentistas, que destacaron eventos de la canción como "expresivos" o "interesantes", pero sin conectarlos significativamente con su versión sobre el "mensaje" global que comunica la pieza musical.

I: ¿Por qué levantaste la mano en este momento? [Solo de guitarra]. R: Lo que la guitarra está haciendo en el solo, está como llevando [la canción] al sentimiento siniestro que sonó antes... 
[Más adelante en la entrevista]

I: ¿De crees que se trata esta canción?

R: No estaba prestando mucha atención a la letra, pero cuando lo

hice él estaba hablando de disfrutar y del poder de la música.

[Mujer, británica sobre “Siren’s call”].

Sin embargo, se hizo evidente que la mayoría de los oyentes asumieron, al igual que los cantantes, que para responder a la pregunta "¿de qué se trata esta canción?", debían buscar la respuesta en los fragmentos que recordaran de la letra de la misma. De hecho, en sus respuestas se nota que consideraron que si la canción contenía una narración, entonces el protagonista de la misma era el cantante. ${ }^{5}$ Esto ocurrió incluso en aquellos casos en los que los participantes reportaron no haber prestado mucha atención a la letra de la canción. Sin embargo, -tal como se esperaba-, los oyentes extranjeros (aquellos cuyo primer idioma no era inglés), tuvieron dificultades con esta estrategia.

Las diversas maneras como los oyentes integraron la información obtenida a partir de la música y la información de la letra para construir su interpretación sobre el mensaje que "transmitía" cada canción es elaborada con mayor detalle en la siguiente sección.

\section{¿Hasta qué punto la interpretación que hacen los oyentes acerca del "mensaje" de la canción coincide con el que intentaron comunicar los músicos?}

Como se ha mostrado hasta este punto, los oyentes no construyeron su interpretación sobre el mensaje de la canción a partir de una simple "suma" de los eventos musicales que destacaron, pues no sólo muchas veces no percibieron dichos eventos como expresivos de algún mensaje o emoción; sino que además no integraron las inferencias que hicieron sobre el significado de cada evento en sus reflexiones acerca del significado o mensaje global de la canción. ¿Cómo es posible entonces que los oyentes lograran "descifrar" (o "construir", para usar un término más adecuado) el mensaje de la canción, si no fue a partir de los momentos que destacaron? La respuesta que propongo es que los oyentes, al igual que los músicos instrumentistas, fueron sensibles al vibe o feeling general de la canción, -aquello que Hanslick llama una "agitación inespecífica" (citado en Cook, 2001: 180)-, y asociaron este feeling con un referente simbólico, lo cual les permitió transformar esta vaga agitación en lo que podríamos llamar "música con significado".

5 Cuando se les preguntó cómo se imaginaban el video de la canción, invariablemente los participantes asignaban el rol protagónico del mismo al cantante de la banda. 
Tal como se ha dicho, usualmente este referente simbólico fue buscado en la letra de las canciones. Es natural que las letras de las canciones tengan ese rol central en las mentes de los oyentes no sólo porque cognitivamente facilitan la comprensión de una narración, sino porque su medio de transmisión es la melodía, la cual resalta perceptualmente en la estructura musical de cualquier canción (de hecho, los demás instrumentos están ahí para acompañar a la melodía vocal). Así pues, el uso que los oyentes hicieron de las letras como referentes simbólicos para interpretar la "agitación" que propone la música produjo cinco posibles escenarios de construcción de significados:

1. Aquellos oyentes que no comprendieron o no le prestaron atención a la letra de la canción, construyeron su interpretación sobre el mensaje que ésta expresa en una asociación del feeling o vibe de la canción con alguna convención cultural que les diera alguna "pista" sobre su significado. En estos casos la respuesta de los oyentes a la pregunta sobre el mensaje de la canción, fue expresado en términos muy vagos relacionados con dicho feeling:

I: ¿De qué crees que se trata esta canción?

R: [Piensa por un rato]... Parece ser una canción relajada, en realidad, no creo que haya algún mensaje en ella.

I: ¿Crees que la canción expresa alguna emoción en particular?

R: No, no creo.

I: Si esta canción tuviera un video, ¿Qué imágenes tendría?

R: Un club de jazz, un lugar para cenar, algo así [...] Es como música que escuchas de fondo mientras comes.

[Hombre británico, sobre la canción "Black Coffee”]

Estas asociaciones entre la música y referentes culturales tan amplios implicaron que el nivel de coincidencia entre la interpretación de estos oyentes sobre el mensaje de la canción y el mensaje que intentaban comunicar los músicos (en particular los cantantes), fuera muy bajo. De hecho, se puede argumentar que sólo coincidieron en el nivel general de activación (energía, vibe o feeling) que propone la canción. Así, en el ejemplo anterior contrasta la interpretación que hace el oyente de la canción como una canción "relajada", con la intención de los músicos, que piensan en ésta como una canción sobre una mujer deprimida. Evidentemente hay una diferencia grande entre estar relajado y estar deprimido, pero ambos son estados afectivos con un bajo nivel de activación.

2. Una segunda posibilidad es que el oyente no pudiera invocar alguna asociación simbólica que le permitiera dar sentido al feeling que proponía la canción. 
Esto sólo ocurrió en unos pocos participantes extranjeros que no sólo tuvieron dificultad para entender la letra de la canción, sino que además probablemente no estaban familiarizados con el estilo musical de las bandas: los participantes de origen chino. En este escenario el participante se declaraba incapaz de descifrar cuál era el mensaje de la canción.

I: ¿¿De qué crees que se trata esta canción?

R: No puedo responder a esta pregunta, porque no pude entender la letra $100 \%$. [...] Creo que están tratando de comunicar algo, pero no sé que es... puede ser felicidad o infelicidad, pero no puedo saberlo porque eso depende de la letra.

[Hombre de origen chino, sobre la canción "Black Coffee"]

3. Un tercer escenario se presentó cuando el oyente solamente comprendió un pequeño fragmento de la letra que no estaba en el coro de la canción. En estos casos (típicos, pero no exclusivos de oyentes cuyo primer idioma no era inglés), los oyentes tendieron a construir interpretaciones muy idiosincrásicas sobre el mensaje de la canción, o remotamente coincidentes con lo que intentaron comunicar los músicos:

"El cantante dijo una palabra muy fuerte en un momento ["fuck"], por lo tanto, esta canción debe tratarse de que él tiene mucha rabia"

[Participante de origen chino, sobre la canción "Give me some loving"]

A partir de la letra, yo creo que esta es una canción sobre el desear. Eso de "ten cuidado con lo que deseas, porque puede que lo consigas".

[Participante británico, sobre la canción "Give me some loving"]

4. Una última posibilidad, que es la más favorable para que las intenciones comunicativas de los músicos se hagan realidad en las mentes de su audiencia, se presentó cuando el oyente comprendía la letra de la canción y usaba particularmente las palabras que aparecen en el coro para construir su inferencia sobre el mensaje de la canción. Esto ocurrió con más frecuencia en los oyentes cuyo idioma nativo era inglés, y que además estaban familiarizados con los géneros musicales interpretados por las bandas.

El hecho de que este tipo de oyentes recurrieran al coro como fuente de referentes facilitó mucho su comprensión del mensaje de la canción, pues estructuralmente en las canciones de música popular el coro se interpreta de tal manera que sobresale musicalmente, es presentado varias veces a lo largo de la pieza, y usualmente cumple la función de sintetizar el significado que se intenta transmitir. 
I: ¿¿De qué crees que se trata esta canción?

R: Evidentemente a él realmente le gusta esta chica. No sé si sea intencional o no, pero creo que hay unos momentos más controlados, como si él estuviera un poco tenso o algo [...] Pero en otros momentos es como si fuera "Oh, maldita sea, esto es lo que estoy sintiendo", como si fuera honesto.

[Mujer británica, sobre "Give me some loving"]

En este ejemplo es claro cómo esta mujer hace uso de la narrativa que aparece en la letra y de las variaciones en el feeling de la canción (que tiene momentos juguetones, jazzy, otros melódicos y otros "pesados"), para construir una interpretación sobre el mensaje de la canción que coincide bastante con la narración que construyó el cantante de la banda.

Como puede observarse en estos cuatro escenarios, la letra actuó como un referente simbólico predominante en las construcciones que los oyentes hicieron sobre el mensaje expresado por las canciones. Tanto fue así, que con frecuencia ocurrió que si el oyente percibía que el feeling de la música y el mensaje de la letra coincidían, podía ignorar momentos de la canción aparentemente "contradictorios". Por ejemplo, una oyente británica afirmó que "Black Coffee" era "una canción triste", a pesar de haber afirmado antes que el solo de saxofón tenía frases "alegres".

5. Sin embargo, no se debe sobreestimar el poder de la letra. No se trata de que las canciones de música popular sean significadas como meros textos de contenido verbal en el que la música es simplemente un medio o un accesorio. Es claro, sobre todo a partir de las respuestas de los participantes a la canción "You took advantage of me", que los oyentes tuvieron en cuenta la contradicción entre una letra aparentemente llena de rabia e indignación, con una música que sugiere un estado de ánimo alegre. En este quinto escenario, la mayoría participantes que comprendieron la letra mencionaron esta contradicción, y concluyeron que el mensaje de la canción era irónico o era absurdo.

Creo que es una canción sarcástica, pero es muy movida, ella está cantando sobre alguien que se aprovechó de ella, y ella realmente no le gusta eso.

[Mujer británica, sobre "You took advantage of me"]

No puedo saber si ella está enojada porque él la amó y luego la dejó o si ella está medio bromeando... Eso me confundió un poco [...] La canción es un poco dramática, pero al final ellos ponen esa frase juguetona... Eso me hace pensar que sólo estaba bromeando.

[Mujer británica, sobre "You took advantage of me"] 


\section{Discusión}

\section{¿Tiene significado la música?}

Contestar la pregunta con la que la comienza esta investigación es evidentemente una empresa muy ambiciosa, pero es posible discutir tres respuestas hipotéticas a partir de los resultados obtenidos en esta exploración.

La primera equivaldría a adoptar lo que Meyer (1956) denomina una posición "absolutista”, según la cual la música no se refiere a ningún objeto exterior, sino que su significación radica en la referencia a otros sonidos musicales. El hecho de que en ocasiones los participantes (tanto músicos como oyentes) no percibieran que los estímulos musicales tenían significado concreto, parece apoyar esta conclusión. El problema con adoptar esta solución es que en muchas otras ocasiones los oyentes sí asignaron significados extramusicales tanto a los eventos musicales particulares como a las canciones como objetos totales.

La segunda respuesta sería afirmar que la música expresa emociones básicas (Kivy, Davies citados en Cook 2001: 179). Los autores que defienden esta postura asumen en términos generales la tesis de que la forma de la música es de alguna manera similar a la forma con que expresamos las emociones en otros medios como la voz humana. Como se mencionó antes, en el campo de la psicología de la música autores como Juslin y Laukka (2003) han asumido esta postura, según la cual la música expresa emociones discretas mediante el uso de parámetros acústicos similares a los de la expresión emocional en la voz. Los resultados encontrados en esta indagación no apoyan claramente esta tesis. En primer lugar, porque muchas veces la música no fue percibida por los participantes como expresiva de emociones concretas. Segundo, porque cuando sí fue percibida de esa manera, no siempre los participantes coincidieron en sus apreciaciones sobre el tipo de emoción expresada (lo cual se esperaría si estuvieran filogenéticamente preparados para percibir emociones auditivamente). Y, en tercer lugar, porque en la mayoría de ocasiones el vocabulario que usaron los participantes para hablar del carácter de la música no correspondió a emociones básicas, sino más bien a conceptos más abstractos como intensidad, energía, relajación, tensión, etc.

Esta última consideración nos lleva a la tercera posible respuesta a la pregunta sobre la significación musical: la música no tiene un significado inherente, pero puede sugerir "gestos y expresiones de emociones del cuerpo humano" (Clynes, Scherer, citados en Sloboda y Juslin 2001: 93). Esta perspectiva explica mejor los resultados de este estudio, siempre y cuando asumamos que estas "expresiones y gestos" no son manifestados psicológicamente como emociones discretas (tal como lo plantea el paradigma neuroevolutivo), sino como una indicación del "afecto central" (core affect): ese estado general de activación o tensión y de pla- 
cer/displacer que según la teoría de Russell y Barrett (1999) subyace a cualquier expresión emocional, y que podemos describir con adjetivos muy generales y antinómicos como: agitado / calmado, tenso/ relajado, agradable/ desagradable.

Según esta perspectiva teórica, para experimentar o percibir una emoción es necesario que el sujeto realice un "análisis conceptual del afecto central" (Barrett, 2006: 22); es decir, que categorice esa sensación imprecisa de tensión/relajación, placer/displacer mediante un acto conceptual que le de un nombre y le permita saber qué emoción está sintiendo o percibiendo. De manera análoga podríamos suponer, tal como lo hace Francès en su teoría de la potencialidad semántica de la música (en Nattiez, 1990:126), que los participantes en este estudio experimentaron la música como un fluido de afecto, al cual en algunas ocasiones asociaron e interpretaron mediante una etiqueta verbal.

Esta explicación concuerda mejor con los hallazgos de este estudio, pues explica porqué en muchas ocasiones los participantes hablaron de la música sólo en términos de fuerza, tensión, feeling, vibe, subidas y bajadas de energía, pero no en términos de emociones discretas. Esta hipótesis también da cuenta de aquellos casos en los que los oyentes acertaron en el nivel de activación propuesta por los músicos en el feeling de la canción (por ejemplo: la percibieron como rabiosa o agitada en vez de alegre), pero no en el tipo de emoción concreta que aparecía en la narrativa de la letra.

Esta hipótesis permite suponer además que el mecanismo para la inducción de emociones mediante la música y el mecanismo para su expresión y percepción es básicamente el mismo. Así pues, la teoría de la expectativa de Meyer (1956) plantea que la música induce emociones a través de la elicitación de cambios en el nivel de activación del oyente; estos cambios para Juslin y Sloboda (2001:93) constituyen proto-emociones, los cuales al ser asociados con un referente simbólico se convierten en emociones propiamente dichas. De igual manera, en el caso de la expresión y percepción de emociones, los niveles de tensión/agrado que presenta el fluido musical son susceptibles de ser interpretados de diversas formas de acuerdo al referente simbólico que el sujeto les adjudique, siempre y cuando coincidan con la valencia y dirección de la activación. Por ejemplo, no es posible escuchar música "agitada y con mucha energía" y deducir que expresa una emoción relajada como la "ternura". También es posible sin embargo, que esa tensión musical no sea percibida como expresiva de emociones, si el oyente o el músico no le asigna un referente simbólico concreto. Como fue el caso de los instrumentistas que hablaban de eventos musicales muy "energéticos", pero sin poder elaborar más allá de esta idea abstracta.

\section{¿Cómo se comunica el significado musical?}


Según las teorías de Meyer (1956) y de Huron (2006), músicos y oyentes construyen el significado de la música a partir de aquellos momentos en los que la música viola o posterga las expectativas que ha generado. En el caso de este estudio, no es claro hasta qué punto los eventos destacados con mayor frecuencia por los participantes les resultaban "sorprendentes" o "inesperados" (algunos participantes, por ejemplo, afirmaron explícitamente que sabían que la música iba a variar, pero aún así destacaron esos fragmentos). Lo que sí es claro es que tanto músicos como oyentes resaltaron prioritariamente aquellos instantes en los que la música cambiaba. Esto sugiere que algunos de estos eventos resultaron ser prominentes por razones que no dependen necesariamente de decisiones expresivas conscientes por parte de los músicos. ${ }^{6}$

Sin embargo, y tal como se afirmó en el apartado de resultados, la existencia de un buen número de eventos que fueron destacados, tanto como por los músicos como por los oyentes, significa que a pesar del peso tan importante que tuvieron las letras en los procesos de significación de las canciones, la estructura musical también aportó de manera objetiva a la experiencia de los participantes.

Este rol central que tuvieron las letras en los procesos de construcción del mensaje o significado de las canciones era de esperarse, por supuesto. No obstante, es interesante anotar al mismo tiempo que no todos los músicos (sobre todo los instrumentistas) ni todos los oyentes estuvieron atentos a las letras de las canciones; incluso algunos participantes británicos, que no tendrían problema en entender las palabras cantadas por los vocalistas, reportaron no haberles prestado atención. Este hallazgo sugiere entonces que aquellos estudios que han adoptado un enfoque semiótico, intentando encontrar el significado de la música popular exclusivamente en la letra (Ostlund \& Kinnier, 1997; Stewart, 2005), o aquellos estudios psicológicos que buscan correlaciones entre letras de la música y el comportamiento de los adolescentes (Anderson et al., 2003, Martino, et al., 2006), han sobredimensionado la importancia del componente verbal de las canciones en la manera como los oyentes las significan.

Los hallazgos de este estudio sugieren que en el proceso de significación de las canciones, la interacción entre los contenidos de la letra y el "tono afectivo" de la música es compleja, pues tal como lo han encontrado otros autores, (Omar y Peynircioğlu, 2006; Morton y Trehub, 2007), aquí se halló evidencia de que los oyentes son sensibles al carácter de la música y al mensaje de la letra, que son capaces de identificar sus coincidencias y contradicciones, y que no siempre privilegian una fuente de significación sobre la otra. Sin embargo, una explicación

6 Cabe también mencionar que a diferencia de la predicción de Meyer, el fenómeno de inducción de emociones fue bastante escaso en esta investigación: solamente un par de ocasiones dos oyentes aseguraron haber sido conmovidos por las canciones y tener reacciones físicas que calificaron como "emociones". 
completa de las interacciones de congruencia, complementariedad y oposición entre música y letra sobrepasa los objetivos y alcances de este estudio; una indagación completa de esta dinámica requiere del uso de diseños experimentales factoriales como los mencionados.

Para sintetizar la respuesta que se elaboró en este estudio a la pregunta sobre cómo se comunica el significado musical, se construyó un modelo del proceso de construcción y negociación de significados de la música con letra, el cual se basa en la teoría semiótica Nattiez (1990). Este modelo está representado gráficamente en la figura 1.

El lado izquierdo del diagrama representa lo que Nattiez denomina el proceso poyético, es decir el proceso de creación de la música. Aquí se observa cómo el hecho de que tanto instrumentistas como cantantes estén mínimamente de acuerdo en el feeling, género y estilo de la canción, hace posible que en conjunto, estos músicos produzcan la ilusión de que la canción "contiene" un significado o mensaje unificado; todo esto a pesar de que en realidad cada integrante de la banda aporta diferentes elementos e intenciones particulares, y de que no todos conozcan la narrativa de la letra.

Esta ilusión se concreta en los sonidos: el objeto musical, que corresponde con lo que Nattiez llama "la huella material", y que se representa mediante un rectángulo vertical en el diagrama.

El lado derecho del diagrama representa lo que para Nattiez es el proceso estésico, es decir, los procesos de construcción de significado que hacen los oyentes, el cual empieza a partir de su percepción selectiva de una o varias de las cualidades físicas presentes en la huella material. En este caso, el proceso estésico se descompone para representar los cinco escenarios posibles descritos en la sección de resultados: 1) que el oyente reporte que no captó el significado de la canción; 2) que exprese el significado de la canción en términos muy generales, como su feeling o tono emocional; 3) que construya un significado idiosincrásico; 4) que construya un significado muy coherente con el que intentaron comunicar los músicos; o 5) que reporte sentirse confundido porque percibe que la canción es irónica o absurda.

En síntesis, este modelo contradice los supuestos de la tradición musicológica y de las teorías funcionalistas, en el que la comunicación musical está garantizada por la supuesta "genialidad" del compositor o el talento de sus intérpretes. Pero al mismo tiempo, el modelo contradice aquellas posturas doxológicas o ingenuamente constructivistas según las cuales el significado de la música es completamente arbitrario, y por tanto cada sujeto o grupo social puede significar la música de maneras infinitamente diferentes. 
Por el contrario, este modelo enfatiza que las intenciones de los músicos dejan "huellas" objetivas (cualidades físicas) en el material musical; y cómo los oyentes construyen significaciones que a pesar de ser muy variadas, están limitadas por lo que dicha materialidad de la música y de la letra permiten interpretar, de tal manera que ciertas interpretaciones resultan más probables o adecuadas que otras (Clarke, 2005). ${ }^{7}$

Resulta paradójica esta idea de que existe una comunicación que es parcial, condicionada y contingente, cuando además no siempre hay una intención comunicativa por parte del músico. Pero tal vez podríamos considerar esto como una cualidad normal de la manera como circulan en la sociedad los significados de los objetos artísticos en general.

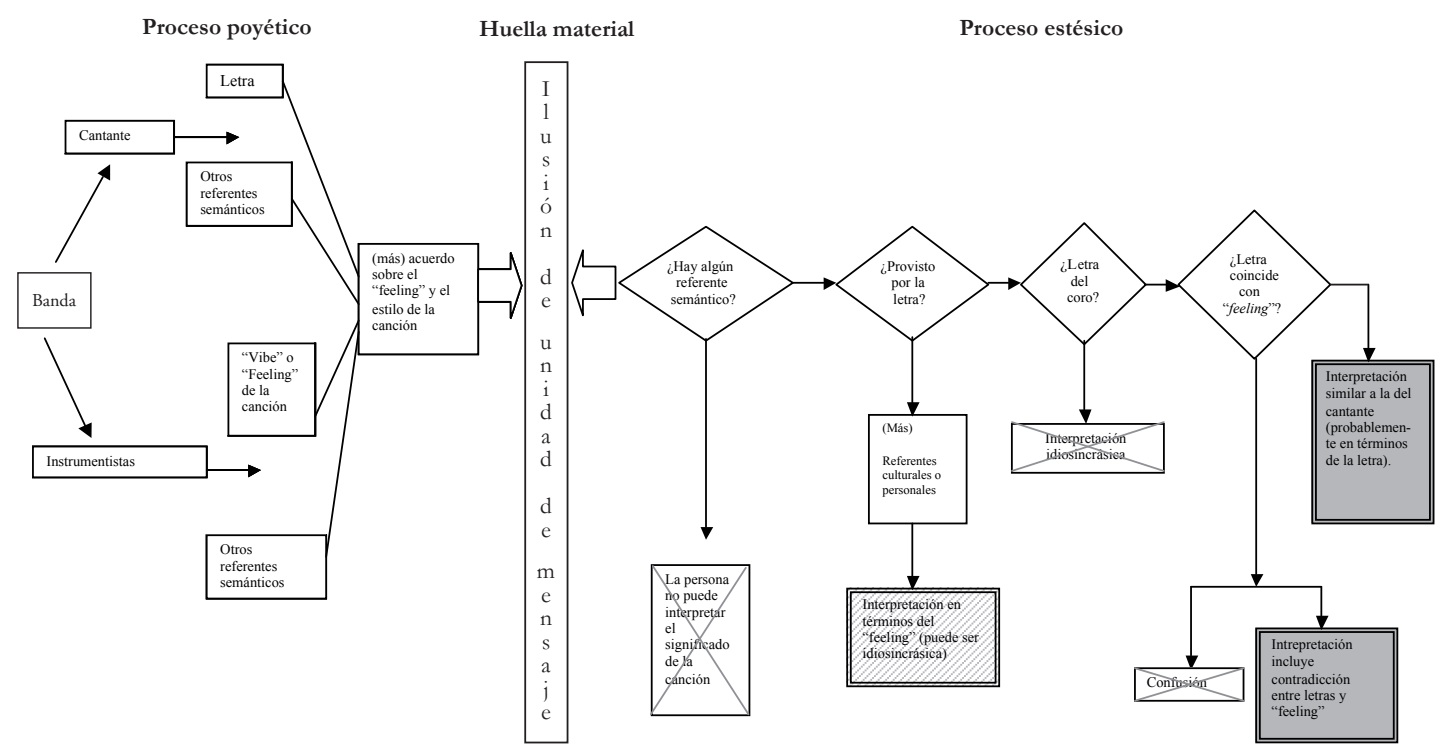

Figura 1: Modelo de comunicación de significado musical en la música popular

\section{Conclusiones}

El primer objetivo de este estudio era examinar la validez de un modelo conceptual constructivista y crítico con respecto a los supuestos epistemológicos que subyacen al paradigma dominante en las investigaciones de psicología de

7 Por ejemplo, el ritmo marcado de la música techno, permite significarla más fácilmente como música para bailar de forma agitada, que como música para arrullar un bebé. 
la música sobre la construcción y comunicación de significados musicales. De manera coherente con esta postura crítica, el segundo objetivo de la investigación consistía en evaluar la eficacia de la adopción de un enfoque metodológico cualitativo para indagar dichos fenómenos.

Esta decisión metodológica tiene como consecuencia que las conclusiones de este estudio no poseen el alcance explicativo que pretenden los estudios experimentales como los de Juslin (2000), en los cuales el control y la medición de múltiples variables permiten modelar y cuantificar sus relaciones de manera precisa. Es por esta razón que desde el comienzo se caracterizó al presente estudio como exploratorio y sus conclusiones deben ser tomadas como conjeturas elaboradas a partir de la revisión teórica y de la evidencia empírica recogida.

Es posible además enumerar otros factores que limitan la validez de las conclusiones de la presente investigación: a) la baja representatividad estadística de las bandas, canciones y participantes escogidos para el estudio; b) El nivel de competencia en idioma inglés de los participantes de la categoría oyentesextranjeros era claramente menos bueno que el de los británicos, pero aún así era lo suficientemente alto como para estudiar en una universidad británica; c) La artificialidad de la situación propuesta en el procedimiento de la entrevista; y d) las dificultades que implica el uso de reportes verbales para dar cuenta de procesos cognitivos implícitos como la percepción y la significación.

A pesar de estas consideraciones, en términos generales es posible evaluar las decisiones metodológicas que se tomaron como acertadas, pues el uso de estímulos musicales completos y con sentido (canciones) en vez de fragmentos elementales, el uso de entrevistas con preguntas abiertas en vez de listas cerradas de opción múltiple, y la rigurosidad con que se examinaron las justificaciones que proponían los participantes para destacar eventos en la música, permitieron en últimas acercarse de manera más desprejuiciada a la experiencia subjetiva de los oyentes y músicos, y aproximarse a la comprensión de los complejos procesos de construcción de significados de objetos inherentemente complejos como lo son las canciones con letra.

Así pues, los resultados de esta investigación sugieren que es posible estudiar el proceso de construcción de significados de la música sin caer en el extremo de los estudios psicosociales, sociológicos, o antropológicos que discuten los usos sociales de la música sin referirse a las cualidades específicas del material musical (Serrano, 1996; Patińo, et al., 2005), ni en el extremo de los estudios musicológicos que pretenden encontrar el significado en los detalles estructurales de dicho material, ignorando por completo la experiencia de los oyentes reales (e.g. McClary, citada en DeNora, 2000). 
El enfoque metodológico aquí adoptado buscó además proporcionar un mayor nivel de validez ecológica a las conclusiones, pues se intentó acercarse a las maneras como tanto músicos y oyentes significan la música en sus vidas cotidianas. Este propósito no se cumplió completamente, pues de entrada la situación propuesta por el investigador era artificial. Es poco probable que estas personas en su día a día escuchen canciones prestando tanta atención a los detalles y pensando conscientemente en su significado como en el procedimiento planteado durante la entrevista. Aún así, los resultados de este estudio permiten conjeturar, con mayor claridad, que los estudios experimentales cómo en la vida cotidiana las personas construyen y asignan significados a la música que escuchan, componen o interpretan a partir de dinámicas de negociación de sentidos en los cuales intervienen tanto los factores estructurales de la música, como los diversos referentes simbólicos que el sujeto tenga a mano.

A pesar de que en la información recabada en las entrevistas no se profundizó en el bagaje cultural con que contaba cada participante, aún así se hizo evidente que en el proceso de construcción de significados musicales los sujetos hicieron uso de referentes semánticos que surgían de su familiaridad con los géneros, las letras y las convenciones estilísticas de las dos bandas que se les presentaron. Esto permite inferir que en la escucha de música popular en la vida cotidiana se emplean también referentes semánticos de origen cultural para la construcción de significados musicales. Pero probablemente en tales circunstancias las fuentes de significación a las que se tiene acceso son múltiples, contingentes, y disputan su relevancia en la mente del sujeto haciendo que éste signifique la música de diferentes maneras a partir de un proceso en el que asocie el feeling de la música con referentes como: sus estados subjetivos (e.g. recuerdos), el discurso que exista sobre el valor estético de la música y el artista en cuestión, las discusiones con otras personas sobre cómo interpretar las letras, las imágenes del videoclip de la canción, las connotaciones culturales de la situación en que el sujeto escucha la música, etcétera, etcétera. Desde la perspectiva teórica y metodológica aquí adoptada se desprende entonces que el contexto cultural no es simplemente una variable que se agrega como un factor causal más entre la lista de variables que afectan la expresión y percepción de significados musicales (Juslin, 2003); más bien el contexto cultural constituye la matriz simbólica fundamental a partir de la cual se significa la música.

En este mismo sentido, es posible afirmar que el primer objetivo de la investigación: poner a prueba la fuerza explicativa de un modelo teórico constructivista, se cumplió satisfactoriamente. La perspectiva conceptual defendida en este estudio es lo suficientemente amplia como para dar cuenta de los hallazgos de las 
investigaciones del modelo funcionalista, cuando encuentran por ejemplo, que los oyentes perciben la música como expresiva de emociones. Pero a la vez este modelo sirve para explicar por qué en algunas ocasiones diversos oyentes no están de acuerdo sobre la emoción expresada en una misma pieza, o porqué a pesar de que los músicos no logran articular claramente sus intenciones comunicativas, logran tocar de maneras que son percibidas como "expresivas" por sus oyentes.

Este modelo constructivista ayuda además a elaborar conjeturas para comprender fenómenos que se escapan al alcance del paradigma dominante en la psicología de la música. Por ejemplo, desde esta perspectiva es posible comprender cómo es posible que en los países latinoamericanos las personas disfruten (en ocasiones de manera muy apasionada) de música que tiene letras en idiomas diferentes al español, y que por lo tanto, no entienden. Esta investigación permite encontrarle sentido a esta situación aparentemente absurda, pues se encontró evidencia de que incluso algunos sujetos que podían entender la letra completamente, optaron por no hacerlo y recurrieron a otros referentes (como el "feeling" de la música), para inferir el "mensaje" de la canción que escucharon.

Una perspectiva interesante para investigaciones futuras sería precisamente emplear las premisas teóricas y metodológicas de este estudio para estudiar con mayor detalle las experiencias cotidianas de construcción de significado musical. Algunos ejemplos: conocer las razones por las cuales las personas experimentan emocionalmente una obra musical hasta el punto de sentirla como su "favorita", o hasta el punto de sentir que la detestan; entender las razones por las que un músico considera que ha tocado de manera particularmente apasionada o expresiva; indagar cuáles son las circunstancias en que las personas viven con mayor intensidad emocional a la música, o por el contrario, explorar la experiencia de aquellos sujetos que no parecen interesarse ni disfrutar la música.

Es innegable que un enfoque funcionalista como el que predomina en los estudios de psicología de la música no cuenta con la flexibilidad suficiente para responder preguntas de investigación como las planteadas en el párrafo anterior, pues no puede dar cuenta de la multiplicidad de significados que tiene la música en la vida cotidiana. Este tipo de teorías no han logrado hacer una ruptura epistemológica que los libere de los supuestos de de la tradición musicológica.

Afortunadamente, en los últimos años han empezado a aparecer en la musicología, en la sociología de la música y en la psicología de la música, nuevas perspectivas como las defendidas en este artículo, las cuales han resultado más útiles para dar cuenta de la complejidad de los fenómenos de significación de la música (bien sea popular o clásica). Así pues, teóricos como Small (1999), Cook (2001), Clarke (2005), DeNora (2000) y Dibben $(2001,2006)$ entre otros, han 
empezado a romper con la tradición preponderante para confluir alrededor de tesis como las siguientes, que coinciden en gran medida las conclusiones generales del presente estudio, y son por tanto presentadas como reflexión final:

- El significado de la música, bien sea de tipo emocional o de otro tipo, no es inherente a la misma, es contingente, y no puede ser explicado exclusivamente a partir de su estructura, ni de mecanismos perceptivos de origen evolutivo.

- Por el contrario, es fundamental considerar el contexto histórico cultural y las circunstancias particulares de producción y escucha de la música para discutir su significado.

- La música es percibida como "portadora" de emociones en gran medida gracias a una actitud de escucha intencional del oyente, especialmente cuando escucha música de su agrado.

- Más que estar "cargada" de emociones, la música puede ser usada como un medio o "tecnología" para experimentar las emociones bien sea de forma vicaria (imaginándose el sentimiento del músico que la interpreta, por ejemplo), o para vivirlas en carne propia (por ejemplo, usando la música para relajarse o para desahogarse). ${ }^{8}$

8 Sin embargo, y como epílogo a manera de sugerencia, es preciso agregar que a pesar de la fortaleza explicativa de este enfoque, es lícito suponer que éste posee también sesgos que no le permiten conocer el fenómeno de la significación musical a cabalidad. Me refiero al hecho de que la forma como se abordó el problema de la significación musical en esta investigación invitó a los sujetos a elaborar respuestas verbales, sustentadas racionalmente. Se partió entonces de la tesis implícita de que el significado de la música es básicamente un asunto racional, que puede ser articulado mediante una narrativa. Pero es perfectamente posible que en la vida cotidiana las personas hagan uso de otros niveles de significación más implícitos y corporales como los que proponen los autores del paradigma de la cognición enactiva o corporeizada (Varela et al., 1993). Es decir, es posible que (por lo menos en algunos contextos) las personas signifiquen la música no tanto a partir de su "mensaje" como por su capacidad para moverlos, agitarlos, energizarlos, calmarlos, tensionarlos, etc. Claramente en este caso, no sólo la psicología de la música, sino la psicología en general, está apenas empezando a explorar estos fenómenos que parecen escabullirse a la racionalidad de la investigación científica. Entre la creciente lista de autores que han empezado a aplicar estas ideas al campo de la experiencia musical se destacan un buen número de autores iberoamericanos que publican en espańol: Ramón Pelinski (2005), Alicia Peńalba (2005); Isabel Martínez (2008) y Favio Schiffres (2008), entre otros. 


\section{Anexo \\ Estructura musical y letras de las canciones usadas como estímulo}

\section{Banda de Funk-Rock: Canción 1: Siren's Call}

Forma de la canción:

0:00 Introducción (instrumental)

0:15 Estrofa 1

0:32 Pre-coro

0:49 Coro

1:05 Repaso de la Introducción

1:12 Estrofa 2

1:29 Pre-coro

1:45 Coro

2:01 Solo de guitarra

2:18 Puente (con guitarra acústica y canto en falsete)

2:33 Coro

2:55 Coda

Estructura armónica:

Intro

\begin{tabular}{|l|l|ll|l||}
\hline $\mathrm{E} \cdot \mathrm{Bb} \cdot$ & $\mathrm{E}$ & $\mathrm{Bb}$ & $\cdot$ & $\%$ (4 veces) \\
\hline
\end{tabular}

Estrofas

Línea de bajo tocando la misma armonía: E, Bb (8 compases)

Puente

\begin{tabular}{|c|c|c|c|}
\hline G & A & Sección pesada & Sección pesada \\
\hline G & A & C & $\%$ \\
\hline
\end{tabular}

Coro

\begin{tabular}{|l|l|l|}
\hline $\mathrm{G} \cdot \mathrm{A} \cdot$ & $\mathrm{Bb} \cdot \mathrm{C} \cdot$ & $\%$ (4 veces $)$ \\
\hline
\end{tabular}

Letra:

(Estrofa 1):

I'm on top of the world

Today is any other day so this day is followed by tonight 
And there's strange blue glow from a seven-story window drawing me in like a fly to a light

Cannot recall how I got to that door but I find myself standing outside

And as step into I don't care what I do cause a voice tells me that it's alright

(Pre-coro):

The sirens call of the dance floor is pulling me in

The music feels like a rain pour I'm so jumping in

(Coro):

I'm feeling (x2) I'm feeling beautiful [4 times]

(Estrofa 2):

And I'm feeling great

I'm feeling fine

You know the whole room is spinning it's blowing my mind

Could it be what I lose I will find if it's true will I find it in here?

Voices are calling me oh what's the point in me fighting its hold on me clearly I'veStepped into view of power that's true and it won't let me get out alive

[Pre-coro]

[Coro]

[Solo de guitarra]

[Puente]

(Coro final):

And I'm feeling beautiful [4 veces]

\section{Banda de Funk-Rock: Canción 2: Give me some loving}

Forma de la canción:

0:00 Introducción (instrumental)

0:16 Estrofa 1

0:35 Coro ("sección estilo jazzístico")

0:54 Letra: "give me some loving" + Motivo funky en el bajo

1:03 Estrofa 2

1:22 Coro ("sección estilo jazzístico")

1:50 Interludio melódico 
2:09 Sección "pesada"

2:28 Motivo Funky en la guitarra

2:37 Coro ("sección estilo jazzístico")

2:56 Letra: "give me some loving" + Motivo funky en el bajo

3:12 Coda

\section{Estructura armónica:}

Intro y primer verso

\begin{tabular}{|l|l||}
\hline : E $\cdot$ C\# $\cdot$ & B $\cdot \cdot \cdot:$ : \\
\hline
\end{tabular}

Sección de Jazz travieso (tocado en bajo al estilo 'walking bass')

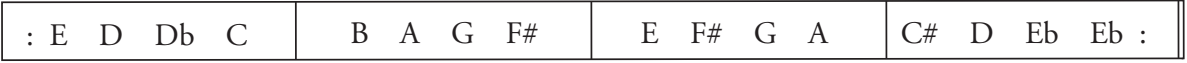

Funky verse (La guitarra y el bajo tocan un riff funky basado en la armonía de la intro)

\begin{tabular}{|l|l|lll|lll|llll||}
\hline$: \mathrm{E} \cdot \mathrm{C} \# \cdot$ & $\mathrm{B}$ & $\cdot \mathrm{D}$ & $\mathrm{Eb}$ & $\mathrm{E}$ & $\cdot \mathrm{C} \# \cdot$ & $\mathrm{B}$ & $\cdot \mathrm{D}$ & $\mathrm{Eb}$ & : \\
\hline
\end{tabular}

Interludio melódico

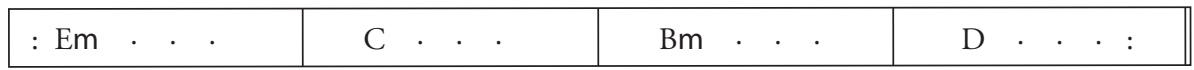

Sección pesada

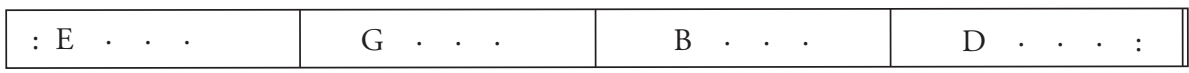

Fin

$\mathrm{Eb} \quad \mathrm{E} \cdot \cdot$

Letra:

(Estrofa 1):

I wake up smiling every morning 'cause I've got you beside me

There's nothing that I'd rather be than naked with you

Watch the sunlight over your skin as it creeps through the window

If stopping time was in my power girl you know that I would

(Coro):

'Cause you know that I can't live without you girl

And I know you want me for your beau,

So just be careful what you wish for

These things have a habit of coming of coming true

Give me some loving

Yeah, you've gotta give me some real sweet loving 
(Estrofa 2):

Baby's got eyes so deep I'm losing my way

You flash that smile at me

And I'm struggling to find the words to say

That your body is so fine I might lose control

Of my mind my shirt my trousers and my senses

In fact fuck it I'll just take them all off

[Coro]

Everyone knows that this world can end bringing you down (down)

But you make it alright with just one flick of your eyes (eyes)

[Coro]

\section{Banda de Jazz: Canción 1: Black Coffee}

Forma de la canción:

0:00 Introducción (instrumental)

0:10 Estrofa 1

$0: 42$ Estrofa 2

$1: 17$ Coro ("man is born...")

1:39 Estrofa 3

2:11 Solo de saxofón

3:19 Solo de bajo

3:50 Coro

4:12 Estrofa 3

4:58 Coda

Estructura armónica:

A

\begin{tabular}{||l|l|l|l|l|}
\hline$: \mathrm{Eb} 7^{(\# 9)} \cdot \mathrm{E} 7^{(\# 9)} \cdot$ & 7 Bars $\%$ & $\mathrm{~Eb} 7^{(\# 9)} \cdot \mathrm{A} 7^{(\# 11)} \cdot$ & $\mathrm{Ab} 7 \cdot \cdot \cdot$ \\
\hline
\end{tabular}

\begin{tabular}{|l|l|l|l|}
\hline$\%$ & $\mathrm{~Eb}^{(\# 9)} \cdot \mathrm{E} 7^{(\# 9)} \cdot$ & $\mathrm{Eb} 7^{(\# 9)} \cdot \mathrm{C}^{\text {alt }} \cdot$ & $\mathrm{F} 7 \cdot \cdot \cdot \cdot$ \\
\hline
\end{tabular}

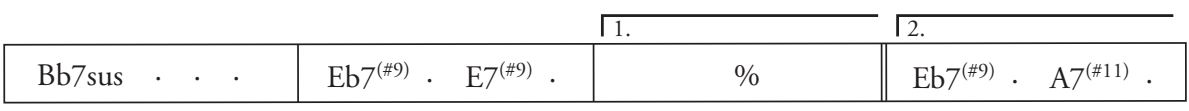


B

\begin{tabular}{||l|l|ll|ll|l|l|}
\hline$: \mathrm{Ab} 7 \cdot \mathrm{Db} 7 \cdot$ & $\mathrm{Eb} 6$ & $\mathrm{C} 7^{(\mathrm{b} 9)} \cdot$ & $\mathrm{F} 7$ & $\mathrm{Bb} 7$ & $\mathrm{~Eb} \Delta \cdot$ & $\cdot$ \\
\hline
\end{tabular}

\begin{tabular}{|l|l|ll|ll|ll|}
\hline $\mathrm{F} \# 7 \cdot \mathrm{B} 7 \cdot$ & $\mathrm{E} \Delta \cdot \mathrm{C \# 7} \cdot$ & $\mathrm{F} \# 7 \cdot \mathrm{B} 7 \cdot$ & $\mathrm{F} 7$ & $\mathrm{Bb} 77^{\text {alt }} \cdot$ \\
\hline
\end{tabular}

\begin{tabular}{|c|c|c|c|}
\hline $\mathrm{Eb} 7^{(\# 9)} \cdot \mathrm{E} 7^{(\# 9)} \cdot$ & $\%$ & $\mathrm{~Eb} 7^{(\# 9)} \cdot \mathrm{A} 7^{(\# 11)} \cdot$ \\
\hline
\end{tabular}

\begin{tabular}{|c|c|c|c|c|c|c|}
\hline $\mathrm{Ab} 7$ & $\%$ & $\mathrm{~Eb}$ & Eb6 & F7 . & G7 & . $\quad C 7^{\text {alt }}$ \\
\hline & & . & $\mathrm{Eb} 7^{(\# 9)}$ & - $\mathrm{E}^{(\# 9)}$ & & $\%$ \\
\hline
\end{tabular}

Solos 12-bar blues en Eb

\begin{tabular}{|c|c|c|c|c|c|}
\hline : $\mathrm{Eb} \cdot$ & $\%$ & & $\%$ & & $\%$ \\
\hline $\mathrm{Ab} 7$. & $\%$ & $\mathrm{~Eb}$ & . . . & . . & C7 . \\
\hline F7 . . . & $\mathrm{Bb} \cdot$ & $\mathrm{Eb}$ & . . & $\mathrm{Bb} 7$ & . . . : : \\
\hline
\end{tabular}

\section{Letra:}

(Estrofa 1):

Feeling mighty lonesome

Haven't slept a wink

I walk the floor and watch the doom

In between I drink

Black coffee

Love's a hand me down brew

Oh I've never known a Sunday

In this weekday room

(Estrofa 2):

Talking to the shadows

1 o'clock to 4

And lord, how slow the moments go

All I do is pour

Black coffee

Since the blues caught my eye

Oh I'm hanging out on Monday

My Sunday dreams to dry 
(Coro):

Now man was born to go a lovin'

A woman's born to weep and fret

To stay at home and tend her oven

And drown her past regrets

In coffee and cigarettes

(Estrofa 3):

I'm mourning all the morning

and mourning all the night

And in between it's nicotine

Not much more besides

Black coffee

Feelin' low as the ground

It's driving me crazy

Just waiting for my baby

To maybe come around

\section{Banda de Jazz: Canción 2: You took advantage of me}

Forma de la canción:

0:00 Introducción de piano lenta

0:14 Estrofa 1 (Cambio de tempo súbito)

0:22 Estrofa 2

0:31 Estrofa 3

0:40 Estrofa 4

0:49 Solo de piano

$1: 25$ Solo vocal en estilo "Scat" + "You took advantage of me"

2:00 Pausa

2:03 Estrofa 1 (lenta)

2:36 Estrofa 2 (Accelerando)

2:51 Estrofa 3

3:01 Estrofa 4

3:09 Pausa

3:12 Dos últimos versos de la estrofa cuatro repetidas (lentas)

3:31 Coda 


\section{Estructura armónica:}

Intro

\begin{tabular}{||l|l|l|l|l|l||}
\hline $\mathrm{Eb} \cdot \mathrm{Bb} \cdot$ & $\mathrm{F} \cdot \mathrm{Eb} \cdot$ & $\mathrm{D} \cdot \mathrm{C} \cdot$ & $\mathrm{F} \cdot \cdot \cdot$ \\
\hline
\end{tabular}

A

\begin{tabular}{||l|l|l|l|l|l|l|}
\hline$: \mathrm{Bb} \Delta \cdot \mathrm{B}^{0} \cdot$ & $\mathrm{C} 7 \cdot \mathrm{F} 7 \cdot$ & $\mathrm{D} 7 \cdot \mathrm{Db}^{0} \cdot$ & $\mathrm{C} 7 \cdot \mathrm{F} 7 \cdot$ \\
\hline
\end{tabular}

\begin{tabular}{|r|l|lll|lllllll|l}
\hline $\mathrm{F} 7$ & $\mathrm{Bb} 7 \cdot$ & $\mathrm{Eb} \Delta \cdot$ & $\mathrm{Ab} 7^{(\# 11)} \cdot$ & $\mathrm{G} 7$ & $\mathrm{C} 7$ & $\mathrm{~F} 7$ & $\mathrm{Bb} \Delta$ & Fsus & $\cdot$ \\
\hline
\end{tabular}

\begin{tabular}{|l||l|l|l|l|l|l|}
\hline $\mathrm{Bb} \Delta \cdot \mathrm{D} 7^{\text {alt }} \cdot$ & $\mathrm{E} \varnothing \cdot \mathrm{A} 7 \cdot \mathrm{D} \varnothing \cdot \mathrm{G} 7 \cdot \mathrm{F} 7 \cdot$ \\
\hline
\end{tabular}

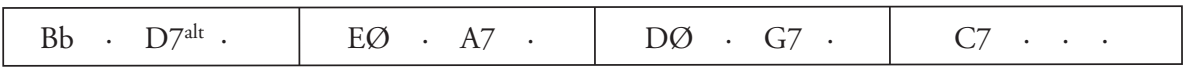

\begin{tabular}{|c|c|c|c|c|c|c|c|c|}
\hline Fsus & . . & $\mathrm{Bb} \Delta$ & $\mathrm{B}^{0}$ & C7 & F7 & D7 & $\mathrm{Db}^{0}$ & . \\
\hline C7 & F7 & F7 & Bb7 & $\mathrm{Eb} \Delta$ & $\mathrm{Ab}^{(\# 11)}$ & G7 & C7 & F7 \\
\hline
\end{tabular}

$\mathrm{Bb} \Delta \cdot$ Fsus .

\section{Letra:}

(Estrofa 1):

I'm a sentimental sap, that's all

What's the use of trying not to fall?

You've made your kill, I have no will

You took advantage of me

(Estrofa 2):

I'm just like an apple on a bough

And you're gonna shake me down somehow

So, what's the use?

You've cooked my goose

You took advantage of me

\section{(Estrofa 3):}

I'm so hot and bothered that I don't know

my elbow from my ear

I suffer something awful each time you go

And much worse when you're near 
(Estrofa 4):

So here I am with all my bridges burned

Just a babe in arms where you're concerned

So lock the doors and call me yours

You took advantage of me.

\section{Glosario}

Acompañar / acompañamiento: ritmo o melodía secundaria que se usa para dar soporte a la melodía principal. En el caso de la música popular, la melodía principal es cantada por el vocalista, y los instrumentos la acompañan.

Acorde / Acorde de tónica: un acorde es una combinación de tres o más sonidos que suenan al mismo tiempo, son clasificados según las normas de la armonía. Un acorde de tónica tiene como sonido principal el primer grado de la escala, el cual a su vez es el punto focal alrededor del cual se organizan los demás sonidos de la obra musical. (Ejemplo: el acorde de Do mayor es el acorde de tónica en una obra que usa la escala de Do).

Andante: término para indicar que una pieza musical se debe interpretar a una velocidad moderadamente lenta.

Apoyaturas: adorno en el cual se toca brevemente una nota musical disonante antes de una nota consonante de duración más larga. El efecto que produce es se que prepara y se acentúa la nota consonante.

Arpegio: tocar un arpegio es tocar las tres o más notas de un acorde una después de la otra en vez de simultáneamente.

Articulación (legato /staccato): manera de tocar una sucesión de notas, que va desde el extremo de tocarlas destacando cada nota de la que sigue (staccato), hasta tocarlas sin que se noten los los "quiebres" entre una nota u otra (legato);

Blues, Blues-jazz: estilo musical afroamericano. Se caracteriza por tener un carácter melancólico y por usar notas "azules" (bemoles) que "chocan" con la armonía. El blues-jazz es una fusión en el que se toca jazz con armonía de blues. 
Blues de 12 compases: progresión cíclica de acordes típica del blues. Los acordes se construyen sobre el primer (I), cuarto (IV) y quinto (V) grado de la escala. Cada acorde se toca durante un compás, y el ciclo se cumple cada doce compases, así:

$\begin{array}{llll}\text { I } & \text { I } & \text { I } & \text { I } \\ \text { IV } & \text { IV } & \text { I } & \text { I } \\ \text { V } & \text { IV } & \text { I } & \text { I }\end{array}$

Cadencia: recurso armónico en el que la música parece "caer" o regresar a un punto de mayor estabilidad o relajación (la tónica), luego de una sección donde había mayor inestabilidad o tensión. Esta "resolución" de la cadencia se usa para dar la sensación de que se cerró una frase o una sección de la obra.

Compás: período de tiempo que se repite de forma cíclica e indica la sucesión regular de pulsos ("golpes") rítmicos de la obra musical.

Dinámica: Variaciones en el volumen (intensidad) de una obra musical, desde muy suave (pianissimo) hasta muy fuerte (fortissimo).

Dirección melódica: Véase "melodía".

Dominante, Séptima de dominante: quinto grado de la escala. Un acorde de séptima de dominante es un grupo de cuatro notas que tiene como nota principal dicho grado, y que produce un efecto de tensión que usualmente se resuelve regresando al acorde de tónica.

Efectos: un dispositivo que se usa como un filtro para alterar a voluntad la señal de un instrumento eléctrico o electrónico. (El efecto más común es la distorsión o fuzz).

Efecto delay ping-pong: El efecto "delay" es un efecto que hace sonar ecos de la señal de sonido. En el caso del delay ping-pong, los ecos parecen "saltar" de un parlante.

Entonación: grado de agudeza de un sonido musical.

Falsete: técnica de canto en la que el hombre alcanza notas agudas más allá de su registro natural. Esto le da un carácter femenino, ligero y depurado a la voz. 
Frase instrumental: una frase es una parte de una melodía que tiene sentido completo. Es instrumental si en ella no hay voces.

Funk, Funky: estilo musical bailable originado en los años sesenta, de origen afroamericano y que enfatiza el ritmo de la batería y el bajo.

Fuzz: un tipo de efecto para guitarra eléctrica en el que la señal del instrumento se distorsiona, (haciendo que suene como un rugido).

Jazz easy-listening: estilo de jazz de fácil escucha, suele usarse como música de fondo. Se caracteriza por tener melodías simples, pegadizas y relajadas e instrumentación poco llamativa.

Jerarquía armónica / Armonía / Tensión armónica / Progresión armónica: la armonía es la forma como se combinan los sonidos simultáneos produciendo acordes. La teoría musical de la armonía estudia las relaciones de tensión y relajación que se producen al tocar acordes (notas simultáneas) y al tocar sucesiones de acordes (progresiones). Entre más estable sea un acorde en el contexto de una obra musical, más importante es en la jerarquía armónica.

Melodía / Dirección melódica (ascendente / descendente): una melodía es una sucesión de notas de altura variable, que en conjunto dan la sensación de tener una dirección organizada y reconocible. La dirección de una melodía es ascendente cuando procede de sonidos graves a sonidos agudos. Es descendente cuando tiene el patrón contrario.

Modo (menor / mayor): tipo de escala (serie ordenada de sonidos) sobre el que se construye una obra musical. Una obra está en modo mayor si las notas de la escala que usa están separadas entre sí usando como modelo los intervalos de la escala de Do mayor. Una obra está en modo menor si usa como modelo los intervalos de la escala de La menor.

Motivo: una corta idea melódica o rítmica que se repite con ligeras variaciones y al ser fácil de identificar, le da identidad y unidad a una obra o una sección de una obra. (Ejemplo: las primeras cinco notas del primer movimiento de la Quinta Sinfonía de Beethoven son su motivo principal). 
Octavas: intervalo entre dos notas en el cual la más aguda tiene exactamente el doble de frecuencia que la más grave.

Pedal Whammy: Un pedal es un efecto que se usa en la guitarra eléctrica para cambiar su sonido y que se acciona con el pie. En el caso del Whammy, se producen súbitamente sonidos que son exactamente una octava más agudos o más graves que la señal original.

Portamento: Una transición de un sonido más agudo a otro mucho más grave o viceversa, sin que exista discontinuidad al pasar de un sonido al otro. La voz o el instrumento parecer "deslizarse" de un sonido a otro.

Resolución de una cadencia: Véase "cadencia".

Riff: término con el que se le denominan a los motivos en géneros como el jazz, el blues y el rock. Es una frase corta que se repite y se usa como acompañamiento.

Ritmo: el patrón cíclico de acentos, duraciones y silencios en la música que dan la sensación de que la música se "mueve" en el tiempo.

Scat: Estilo de canto improvisado común en el jazz en el que el cantante usa sílabas sin sentido.

Séptimo grado de la escala: el grado es el lugar que ocupa cada una de las notas en una escala. El séptimo es el último grado, y da la sensación de que la música va regresar al primero (la tónica).

Sincopas: se hace una síncopa cuando se acentúa una nota en un tiempo (momento) inesperado. Los ritmos asincopados son característicos del jazz.

Ska: Estilo musical originario de Jamaica, y popularizado en Inglaterra y Estados Unidos en los años 70s y 90s. Suena como un "reggae" muy rápido y alegre.

Tempo: Velocidad con que se interpreta una obra musical.

Textura: el número y la forma de relacionarse de las diferentes melodías que suenan simultáneamente en una obra musical. 
Timbre: cualidad de un sonido que permite distinguir la misma nota producida por dos instrumentos musicales diferentes, o por un mismo instrumento tocando la misma nota de formas diferentes.

Walking bass: una forma de interpretar el bajo en jazz en el que se tocan en ritmo constante las notas de la escala en sucesión, (como si estuviera "caminando" por ella).

\section{Referencias}

Adorno, Theodor W. (1990 /1941) On popular music. En Frith, S. y Goodwin, A. (Eds.) On Record: Rock, pop and the written word. (Págs. 301-314). London: Routledge.

Ali, Omar S. \& Peynircioğlu, Zehra F.2006) Songs and emotions: are lyrics and melodies equal partners? Psychology of Music. Vol. 34 (4), 5 I I-534.

Anderson, Craig A., Carnagey, Nicholas L. \& Eubanks, Janie, (2003) Exposure to violent media: the effects of songs with violent lyrics on aggressive thoughts and feelings. Journal of Personality and Social Psychology, Vol. 84 (5), 960-971.

Barrett, Lisa Feldman, (2006) Are Emotions Natural Kinds? Perspectives on Psychological Science, Vol. 1 (1), 28-58.

Black Coffee. Sitio web de la banda del quintento de Jazz "Black Coffee". Tomado el 15 de junio de 2010 de: http://co-lo.night-shade.org.uk/ nick/ new bc sitel

Cellarhigh. Sitio web de la banda de rock "Cellarhigh" en myspace.com. Tomado el 15 de junio de 2010 de: http://www.myspace.com/cellarhigh.

Clarke, Eric F. (1995) 'Expression in Performance: Generativity, Perception, and Semiosis', En Rink, J. (ed.) The Practice of Performance: Studies in Musical Interpretation, (Págs. 21-54.) Cambridge: Cambridge University Press. 
Clarke, Eric F. (2005) Ways of Listening: an ecological approach to the perception of musical meaning. Oxford: Oxford University press.

Cook, Nicholas (1998) Music: A very short introduction. Oxford: Oxford University Press.

Cook, Nicholas (2001) Theorizing musical meaning. Music Theory Spectrum, Vol. 23 (2), 170-95.

DeNora, Tia (2001) Aesthetic agency and musical practice: new directions in the sociology of music and emotion. En Sloboda J.A. y Juslin P. (Eds.) Music and Emotion: Theory and Research (Págs 161-180). Oxford: Oxford University press.

DeNora, Tia (2000) Music in everyday life. Cambridge: Cambridge University Press.

Dibben, Nicola (200 I) What do we hear when we hear music? Music perception and musical material. Musicae Scientiae, "Perspectives on musical meaning", Vol. 5 (2), 161-194.

Dibben, Nicola (2006) Subjectivity and the construction of emotion in the music of Björk. Music Analysis, Vol. 25 (1-2), 171-97.

Dibben, Nicola \& Windsor, Luke (2001) Constructivism in Nicholas Cook's introduction to music: tips for a "new" psychology of music. Musica Scientice Discussion Forum, Vol. 5 (2), pp.43-50.

Ekman, Paul \& Friesen, Wallace V (1975) Unmasking the face: A guide to recognizing emotions from facial clues. Englewood Cliffs, NJ: Prentice Hall.

Frith, Simon (1987) Towards an aesthetic of popular music. En Leepert , R. y McClary, S. (Eds.) Music and society: The politics of composition, performance and reception. Cambridge: Cambridge University Press, pp. 133-172.

Frith, Simon, Straw Will \& Street John (2006) La otra historia del Rock. Barcelona: Robinbook. 
Gabrielsson, Alf \& Lindström, Erik (2001) The Influence of musical structure on emotional expression. En Sloboda J.A. y Juslin P.N. (Eds.) Music and Emotion: Theory and Research, (Págs. 223-248). Oxford: Oxford University press.

Goldstein, Avram (1980) Thrills in response to music and other stimuli. Physiological Psychology, Vol. 8 (19) 126-129.

Huron, David (2006) Sweet Anticipation: Music and the Psychology of Expectation. Cambridge, Massachusetts: MIT Press.

Juslin, Patrik N. (2000) Cue utilization in communication of emotion in music performance: relating performance to perception. Journal of Experimental Psychology, Vol. 26 (6), 1797-1813.

Juslin, Patrik N. (2003) Five facets of musical expression: a psychologist's perspective on music performance. Psychology of Music, Vol. 31 (3), 273-302.

Juslin, Patrik N. (2005) From mimesis to catharsis. Expression, perception and induction of emotion in music. En McDonald, R., Hargreaves D.J. \& Miell D. (Eds.) Musical Communication. (Págs. 85-115). Oxford: Oxford University Press.

Juslin, Patrik N. \& Sloboda John A. (200 I) Psychological perspectives on music and emotion. En Sloboda J.A. \& Juslin P. (Eds.) Music and Emotion: Theory and Research, (Págs. 71-104). Oxford: Oxford University press.

Juslin, Patrik N. \& Laukka, Petri (2003) Communication of emotions in vocal expression and music performance: Different channels, same code? Psychological Bulletin, Vol. 129 (5), 770-814.

KoneČni, Vladimir J., Wanic, Rebekah A. \& Brown, Amber (2007) Emotional and aesthetic antecedents and consequences of music-induced thrills. American Journal of Psychology. Vol. 120 (4), 619-643.

Krumhansl, Carol L. (1997) An Exploratory Study of Musical Emotions and Psychophysiology. Canadian Journal of Experimental Psychology, Vol. 51 (4), 336-352. 
Martin, Peter J. (1995) Sounds and society: Themes in the sociology of music. Manchester: Manchester University Press.

Martínez, Isabel Cecilia (2008) Cognición enactiva y mente corporeizada: el componente imaginativo y metafórico de la audición musical. Estudios de Psicología. Vol. 29 (1), 31-48.

Martino, Steven C., Collins, Rebecca L., Elliott, Marc N., Strachman, Amy, Kanouse, David E., \& Berry, Sandra H. (2006) Exposure to degrading versus nondegrading music lyrics and sexual behavior among youth. Pediatrics Vol. 118 (2), 430-441.

Mcdonald, Raymond, Hargreaves, David J. \& Miell, Dorothy (2002) What are musical Identities, and why are they important? En McDonald, R., Hargreaves D.J., Miell D. (Eds.) Musical Identities, (Págs. 1-20) Oxford University Press.

Meyer, Leonard B. (1956) Emotion and meaning in music. Chicago: University of Chicago Press.

Morton, J. Bruce \& Trehub, S.E. (2007) Children's judgements of emotion in song. Psychology of Music. Vol. 35 (4), 629-639

Nattiez, Jean-Jacques (1990) Music and discourse: Toward a semiology of music. Translated by Carolyn Abbate. Princeton: Princeton University Press.

Ostlund, D.R. \& Kinnier, R.T. (I997) Values of youth: messages from the most popular songs of four decades. Journal of Humanistic Education \& Development, Vol. 36 (2), 83-91.

Patiño, Carlos Darío, Estefan, Estefan, Olga \& Echavarría, Isabel CrisTINA (2005) La identidad metalera: una vivencia emocional. Informes psicológicos, No. 7, 39-55.

Peñalba, Alicia (2005) El cuerpo en la música a través de la teoría de la Metáfora de Johnson: análisis crítico y aplicación a la música. Revista Transcultural de Música Transcultural Music Review, Vol. 9 (2). Descargado el 20 de junio de http://www.sibetrans.com/trans/trans9/penalba.htm 
Pelinski, R. (2005) Corporeidad y experiencia musical. Revista Transcultural de Música Transcultural Music Review, Vol. 9 (2). Descargado el 20 de junio de http://www.sibetrans.com/trans/trans9/penalba.htm

Reguillo, Rossana (2000) El lugar desde los márgenes. Músicas e identidades Juveniles. Revista Nómadas, No. 13, 40-53.

Russell, James A. \& Barrett, Lisa Feldman (1999) Core affect, prototypical emotional episodes, and other things called emotion: dissecting the elephant. Journal of Personality and Social Psychology, Vol. 76 (5), 805-81.

Schachter, Stanley, \& Singer, Jerome E. (1962) Cognitive, social, and physiological determinants of emotional state. Psychological Review, Vol. 69 (5), 379-399.

Scherer Klaus R. \& Zentner, Marcel R. (2001) Emotional effects of music: production rules. En Slodoba and Juslin (Eds.) Music and Emotion: Theory and Research, (Págs. 361-392). Oxford: Oxford University press.

Scherer Klaus R., Banse Rainer, \& Wallbott Harald G. (200 i) Emotion inferences from vocal expression correlate across languages and cultures. Journal of Cross-Cultural Psychology, Vol. 32 (1), 76-92.

Serrano, José Fernando (1996) Abismarse en el suelo del propio cuarto". Observaciones sobre el consumo de Rock entre jóvenes urbanos. Revista Nómadas, No. 4, 28-35.

Shifrres, Favio . (2008) Música, transmodalidad e intersubjetividad. Estudios de Psicología. Vol. 29 (1), 7-30.

Shuker. Roy. (2005) Diccionario del Rock y la música popular. Barcelona: Robinbook.

Sloboda, John A. (I99i) Music structure and emotional response: some empirical findings. Psychology of music, Vol. 19 (2), 110-120.

Slodoba, John A. (1998) Does music mean anything? Musica Scientia, 2 (1), 21-31. 
Slodoba, J.A. \& Juslin, P.N.. (2001) Psychological perspectives on music and emotion. En Slodoba J.A. \& Juslin P.N. (Eds.) Music and Emotion: Theory and Research, (Págs. 71-104). Oxford: Oxford University press.

Slodoba, John A. \& Juslin, Patrik N. (2001) Emotions in everyday listening to music. En Slodoba J.A. \& Juslin P.N. (Eds.) Music and Emotion: Theory and Research, (Págs. 415-429). Oxford: Oxford University press.

Small, Christopher. (1999) El musicar: Un ritual en el espacio social. Tomado en mayo de 2006 de: Revista Transcultural de Música \#4. http://www.sibetrans. com/trans/trans $4 /$ small.htm

Smith, Jonathan A., Jarman, Maria \& Osborn, Mike (1999) Doing interpretative phenomenological analysis. En Murray, M. y Chamberlain K. (Eds.) Qualitative Health Psychology, (Págs. 218-240). London: Sage.

Stewart, James B. (2005) Message in the music: political commentary in black popular music from rhythm and blues to early hip hop. Journal of African American History. Vol. 90 (3), 196-225.

Varela, Francisco J., Thompson, Evan \& Rosch, Eleanor (1992) De cuerpo presente: las ciencias cognitivas y la experiencia humana. Barcelona: Gedisa.

Waterman, Mitch (1996) Emotional Responses to Music: Implicit and explicit effects in listeners and performers. Psychology of music, Vol. 24 (1), 53-67. 